\title{
Synthesis, Photophysical, Electrochemical, and DFT Examinations of Two New Organic Dye Molecules Based on Phenothiazine and Dibenzofuran
}

Periyasamy Kannan ( $\nabla$ atturperiyasamy@gmail.com )

Vaigai Arts and Science Women college

Sakthivel P

Selvam Educational Institutions

Venkatesh G

Muthayammal Memorial College of Arts and Science

Anbarasan PM

Periyar University

Vennila P

Thiruvalluvar Government Arts College Department of Chemistry

Sheena Mary $Y$

Researchers

Kaya S

Cumhuriyet Üniversitesi: Sivas Cumhuriyet Universitesi

\section{Sultan Erkan}

Cumhuriyet University: Sivas Cumhuriyet Universitesi

\section{Research Article}

Keywords: Phenothiazine and Dibenzofuran, Incident photon-to-current efficiency, Photophysical and Photovoltaic properties, Frontier Molecular Orbital, Quantum chemical calculations

Posted Date: December 3rd, 2021

DOl: https://doi.org/10.21203/rs.3.rs-886812/v1

License: (c) (i) This work is licensed under a Creative Commons Attribution 4.0 International License. Read Full License 


\title{
Synthesis, photophysical, electrochemical, and DFT examinations of two new organic dye molecules based on phenothiazine and dibenzofuran
}

\author{
K. Periyasamy ${ }^{1}$, P. Sakthivel ${ }^{2}$, G.Venkatesh ${ }^{3}$, P.M. Anbarasan ${ }^{4}$, P.Vennila ${ }^{5}$, Y.Sheena Mary ${ }^{6}$, \\ S.Kaya ${ }^{7}$, Sultan Erkan $^{8}$ \\ ${ }^{1}$ Department of Physics, Vaigai Arts and Science Women's College, Salem - 636 111, India \\ ${ }^{2}$ Department of Physics, Selvamm Arts and Science College, Namakkal - 637 003, India \\ ${ }^{3}$ Department of Chemistry, MMCAS, Rasipuram, Tamil Nadu-637408, India \\ ${ }^{4}$ Department of Physics, Periyar University, Salem-636 011, India \\ ${ }^{5}$ Department of Chemistry, Thiruvalluvar Government Arts College, Rasipuram - 637408, India \\ ${ }^{6}$ Researcher, Thushara, Neethinagar-64, Kollam, Kerala, India \\ ${ }^{7}$ Department of Chemistry, Cumhuriyet University, Sivas-58140, Turkey \\ ${ }^{8}$ Department of Chemistry, Cumhuriyet University, Faculty of Science, Sivas-58140, Turkey
}

\begin{abstract}
:
New dyes were developed and produced utilizing distinct electron donors (phenothiazine and dibenzofuran), a $\pi$-spacer, and an electron acceptor of cyanoacetohydrazide, and their structures were studied using FT-IR and NMR spectroscopy. Following the synthesis of dye molecules, the photophysical and photovoltaic characteristics were investigated using experimental and theoretical methods. The photosensitizers have been exposed to electrochemical and optical property experiments in order to study their absorption performance and also molecular orbital energies. The monochromatic optical conversion efficiency of (Z)-N((5-(10H-phenothiazin-2-yl)furan-2-yl)methylene)-2-cyanoacetohydrazide (PFCH) found higher than that of (Z)-2-cyano-N'-((5-(dibenzo[b,d]furan-4-yl)furan-2-yl)methylene)acetohydrazide (BFCH), with IPCEs of 58 and $64 \%$ for $\mathrm{BFCH}$ and $\mathrm{PFCH}$, respectively. According to the photosensitizer molecular energy level diagram, the studied dye molecules have strong thermodynamically advantageous ground and excited state oxidation potentials for electron injection into the conduction band of titanium oxide. It was observed that the ability to attract electrons correlated favorably with molecular orbital energy. While density functional theory calculations were used to examine molecule geometries, vertical electronic excitations, and frontier molecular orbitals, experimental and computed results were consistent. Natural bond orbital and nonlinear optical properties were also calculated and discussed.
\end{abstract}


Key words: Phenothiazine and Dibenzofuran; Incident photon-to-current efficiency; Photophysical and Photovoltaic properties; Frontier Molecular Orbital; Quantum chemical calculations

Corresponding author Email id: atturperiyasamy@gmail.com 


\section{Introduction}

According to their low cost, compliance with environmental requirements, and ease of product preparation, dye-sensitized solar cells (DSSCs) based on metal-free organic dyes are gaining popularity at the moment [1-3]. Aside from carrying transmissions, the self-assembled layer of dye molecules on the surface of titania in DSCs controls the quantities of solar photons harnessed and charges separated to a noticeable extent, controlling the resulting energy production [1-5]. The dye factors, which will be the main component of the DSSC, absorb energy and create charged particles. This is normally bound to the porous surface of a semiconductor [6]. Metal free-organic dyes with high efficiency contain at least donor and acceptor units connected by a conjugated system to form a D- $\pi$-A framework which allows intramolecular charge transfer within the system. As a result, photovoltaic characteristics may become more adaptable. To address these problems, metal-free organic sensitizers have been created. The donor-spacer-acceptor structural unit is the fundamental structural unit of organic dye. The donor and acceptor substitutions are separated by a $\pi$-conjugated spacer [6-8]. The donor groups for successful sensitizers, according to the study, must come from the electron-rich aryl amines family, which includes biphenyl, phenylamine, indoline, aminocoumarin, and triphenylamine, among several others. Several solar cell studies have extensively been interested in accessible fabrics for organic photovoltaics that contain triarylamine as an electron donor. These materials have drastically enhanced the absorption rate of the next pv panels, especially dye-sensitized solar cells [9-12].

The phenothiazine ring is nonplanar and it has a butterfly conformation in the ground state, which inhibits molecular accumulation and the existence of intermolecular excimers [1315]. Phenothiazine-based dyes have previously been used in thin-film capacitors, fuel cells, and light-emitting capacitors. The phenothiazine structure has been altered to explore different methods, such as incorporating different substituents and elongating $\pi$-conjugation with some linkers, enabling the production of dyes with suitable optoelectronic properties and significant photovoltaic efficiency. Specifically, phenylbenzimidazole, imidazole, and dibenzofuran derivatives have shown promising in optical and electrical devices [16-20]. Because the production of novel dyes requires awhile, theoretical analysis is regarded as a very effective 
method of investigating the link between the molecular structures and chemical characteristics of dyes. To optimize the optical and electrochemical characteristics, theoretical approaches based on time dependent density functional theory (TD-DFT) and DFT computations have been used. This method is extremely useful in the development of various unique efficient dyes [15-17]. It contributes to the reduction of expense and complexity in traditional hit and trial experimental procedures. The $\pi$-bridge is significant even if it might strengthen a few of the photochemical characteristics of sensitizers by modulating the $\mathrm{E}_{\mathrm{LUMO}}$ and $\mathrm{E}_{\mathrm{HOMO}}$ energy levels while also extending the absorption range. According to Al Sehemi et al., a few metal free-organic dyes with different donor groups have been evaluated and might be promising dyes for DSSCs applications [21]. The photophysical, electrochemical, and photovoltaic properties of solar panels using phenothiazine sensitizers were reported by Jong Min Park and coworkers [22]. Sheng Huang et al. have explored a few phenothiazine dyes with quite effective dye-sensitized solar cells [23]. The influence of $\pi$-linkers on phenothiazine sensitizers for dye-sensitized solar cells was investigated by Formo Buene and their coworkers [24]. Although multiple investigations have looked into the effect of various - spacers, the lack of a bigger data collection is obvious. While these dyes have exceptional capability, their absorption coefficients are usually significant, and dye aggregation, production, and refining are major factors. As a response, metal-free dyes have emerged as an attractive option [24-27]. The major goal of this research was to improve the stability and productivity of metal-free dyes. Based on previous research, we designed and synthesized two novel new dyes based on phenothiazine and dibenzofuran D- $\pi$-A structures with various type end-capping donor moieties and a cyanoacetohydrazide group acting as an acceptor coupled through an acetylene spacer. The dye compounds of PFCH and BFCH were characterized using FT-IR, UV-vis, and NMR studies. Furthermore, these compounds' molecular structures were optimized, and the consequent (IR and UV) values were compared to experimental values. The photophysical and electrochemical characteristics, as well as the photovoltaic parameters, of DSSCs sensitized by these two dyes, were thoroughly studied.

\section{Experimental}

The analytical reagent chemicals used in the synthesis of dye compounds were obtained with purity 90-99\% from Sigma Aldrich Chemicals Private Limited. The proton nuclear 
resonance spectra (400 MHz) with reference to tetramethyl silane for the ${ }^{1} \mathrm{H}$ peak were recorded on a Bruker DRX 400 spectrometer, and the ${ }^{13} \mathrm{C}$ NMR $(125 \mathrm{MHz})$ spectra were recorded on the same spectrometer in DMSO- $\mathrm{d}_{6}$. The IR spectra of the synthesized compounds were recorded using a Perkin-Elmer 597 and 1650 series spectrophotometer in the range 4000-400 cm-1. A UV2501Pc spectrophotometer was used to record the absorption spectra. The incident photon-tocurrent efficiencies were determined in DC mode using monochromatic incident light at $100 \mathrm{~mW}$ $\mathrm{cm}^{-2}$. The current density-voltage $(\mathrm{J}-\mathrm{V})$ characteristics of the DSSCs were calculated using a Keithley 2400 source meter and simulated 1.5 AM sunlight with an output power of $100 \mathrm{~mW}$ $\mathrm{cm}^{-2}$ have used a solar light simulator (PEC-L11, using a 1KW Xe Arc lamp) without the need for a mask. The synthesis scheme for PFCH and BFCH is depicted in Fig.1 and the complete synthesis procedure is presented in the supplemental material. Figure 2 shows the design and construction of dye-sensitized nanocrystalline solar cells.

\section{Computational Details}

Quantum chemical calculations were used to analyze the optimized geometries, electronic distribution, and energy levels of the title dyes in order to demonstrate the relationship between photophysical properties and molecular structures. Density functional theory (DFT) calculations with the B3LYP exchange correlation functional under the 6-311 G++ (d,p) basis set incorporated in the Gaussian 09 software were used to refine the geometrical structures of PFCH and BFCH [28 and 29]. Conceptual Density Functional Theory (CDFT) [29] of Parr can be considered as a useful tool for the prediction of chemical reactivity of compounds. The following equations based on ground state ionization energy (I) and ground state electron affinity (A) of quantum chemical parameters such as chemical potential $(\mu)$, electronegativity $(\chi)$, hardness $(\eta)$ and softness $(\sigma)$ are derived in the light of finite differences approach as defining the chemical potential and hardness as first and second derivatives with respect to number of electrons $(\mathrm{N})$ of total electronic energy (E) at a constant external potential, respectively [30].

$$
\mu=-\chi=\left[\frac{\partial E}{\partial N}\right]_{V(r)}=-\left\{\frac{I+A}{2}\right\}------(1)
$$




$$
\begin{gathered}
\eta=\frac{1}{2}\left[\frac{\partial^{2} E}{\partial N^{2}}\right]_{V(r)}=\left\{\frac{I-A}{2}\right\}------(2) \\
\sigma=\frac{1}{\eta}------(3)
\end{gathered}
$$

Within the framework of Koopmans theorem [31] introduced in 1930s, the negative values of the HOMO and LUMO are approximately equal to the ionization energy and electron affinity, respectively. In the light of this information given, the equations given above are converted to the following equations.

$$
\begin{gathered}
\mu=-\chi=\frac{E_{H O M O}{ }^{+E} L U M O}{2}------(4) \\
\eta=\frac{E_{L U M O}-E_{H O M O}}{2}------(5) \\
\sigma=\frac{1}{E_{L U M O}-E_{H O M O}}-----(6)
\end{gathered}
$$

Electrophilicity index $(\omega)$ presented by Parr, Szentpaly and Liu [32] is based on absolute electronegativity and absolute hardness of chemical species. Chattaraj defined the nucleophilicity index $(\varepsilon)$ as the multiplicative inverse of the electrophilicity index.

$$
\begin{gathered}
\omega=\frac{\chi^{2}}{2 \eta}=\frac{\mu^{2}}{2 \eta}------(7) \\
\varepsilon=\frac{1}{\omega}------(8)
\end{gathered}
$$

Electron donating and electron accepting capabilities of molecules provide important hints about their chemical reactivity or stabilities. Gazquez and coworkers [33] introduced electrodonating power $\left(\omega^{-}\right)$and electron accepting power $\left(\omega^{+}\right)$parameters with the following equations based on ground state ionization energy and electron affinities of chemical systems. 


$$
\begin{aligned}
& \omega^{+}=\frac{(I+3 A)^{2}}{(16(I-A))}------(9) \\
& \omega^{-}=\frac{(3 I+A)^{2}}{(16(I-A))}-------(10)
\end{aligned}
$$

Back-donation energy ( $\left.\Delta \mathrm{E}_{\text {back-donation }}\right)$ can be considered as a tool to predict the electron donating abilities. The mentioned parameter is widely considered in material efficiency studies and is based on chemical hardness of molecules via the following equation [34].

$$
\Delta E_{\text {back }- \text { donation }}=-\frac{\eta}{4}-------(11)
$$

Approximately the $L H E$ was determined from the oscillator strength (f) as given in Equation (12) and $\Delta \mathrm{G}^{\text {inject }}$ have been determined using equation (13)

$$
\begin{array}{r}
L H E=1-10^{-f} \\
\Delta G^{\text {inject }}=E_{\text {dye * }}^{O X}-E_{C B}^{\mathrm{TiO}_{2}}
\end{array}
$$

Where, $E_{d y e *}^{O X} \rightarrow 1^{\text {st }}$ excited state oxidation potential and ${ }_{E_{C B}}^{\mathrm{TiO}}{ }_{2} \rightarrow$ Charge of the conduction band minimum $(\mathrm{CBM})$ of the semiconductor.

$$
E_{d y e *}^{O X}=E_{O X}^{d y e}-\Delta E s_{I C T}------(14)
$$

Where, $E_{O X}^{d y e} \rightarrow$ negative charge of the $\mathrm{E}_{\mathrm{HOMO}}$ and $\Delta E s_{I C T} \rightarrow$ vertical excitation energy and [35-38].

$$
V_{o c}=E_{L U M O}-E_{C B}-----(15)
$$

\section{Result and Discussions}

\section{UV-VIS Absorption Spectra}

Figure 3 shows the UV-Vis absorption spectra of $\mathrm{PFCH}$ and $\mathrm{BFCH}$ in a dilute solution of $\mathrm{CH}_{2} \mathrm{Cl}_{2}$ as well as on $\mathrm{TiO}_{2}$ films, with the characteristic data tabulated in Tables 1 and 2. The 
absorption spectra of dyes are distinguished by absorption bands: one peak appeared at around 290-320 nm, which is attributed to the $\pi \rightarrow \pi^{*}$ transition; second peak occurred at the low-energy region (440-490 $\mathrm{nm}$ ), which is influenced by intramolecular charge transfer (ICT) from the phenothiazine and dibenzofuran donors to the cyanoacetohydrazide acceptor through an aryl $\pi$ bridge [39 and 40]. The polarity of the solvent does no effect on the second peak. This suggests an ICT transition from the donor moiety to the acceptor moiety, despite the fact that the ICT character is low for both dye compounds; such bands can be identified as PFCH and BFCH localized $\pi \rightarrow \pi^{*}$ transitions. The maximal absorption (max) of $\mathrm{PFCH}$ and $\mathrm{BFCH}$ is reported at 317, 468 and 309, $446 \mathrm{~nm}$, accordingly. The absorption spectra of $\mathrm{PFCH}$ and $\mathrm{BFCH}$ in $\mathrm{TiO}_{2}$ films after 10 hours of adsorption are shown in Fig.4. As shown in Figure 4, the maximum absorption peaks for $\mathrm{PFCH}$ and $\mathrm{BFCH}$ in the $\mathrm{TiO}_{2}$ film are at $\lambda_{\max }=494$ and $467 \mathrm{~nm}$, respectively. The absorption bands are red-shifted by 26 and $21 \mathrm{~nm}$, respectively, relative to the solution range. The red shifts in the absorption spectra of PFCH and $\mathrm{BFCH}$ on $\mathrm{TiO}_{2}$ could be attributed to the dyes accumulating on the surface, which is a common occurrence due to the inclusion of an acceptor group in the molecules [41 and 42]. The molar extinction coefficients of the dye molecules were calculated using the Beer-Lambert principle [43]. The two dye molecules have molar extinction coefficients of $21448 \mathrm{M}^{-1} \mathrm{~cm}^{-1}(\mathrm{PFCH})$ and $20796 \mathrm{M}^{-1} \mathrm{~cm}^{-1}(\mathrm{BFCH})$, suggesting their ability to harvest light. The D- $\pi$-A structure stimulates a bathochromic shift in the absorption spectrum and improvements. Furthermore, at the ICT band, of title dye molecules is significantly greater than that of regular ruthenium dye, suggesting excellent light harvesting efficiency. Furan-conjugated spacer units have a higher electron density and lower resonance energy than aromatic ring units, which can improve in transfer of charge. In addition, smaller furan prefers a decrease in molecular dihedral angle and an improvement in molecular planarity. Furthermore, smaller furans desire a decrease in molecular dihedral angle and an improvement in molecular planarity. $\mathrm{PFCH}$ and $\mathrm{BFCH}$ shift continued to improve transfer of charge and molecular planarity their ICT absorption bathochromically and broaden their absorption range in the visible field, expanding their light-harvesting efficiency. The conceptual absorption spectra computed with TD-DFT/6-311G/CAM-B3LYP are seen in Fig.S1 and are perfectly consistent with the experimental ones. The theoretical approach confines TD-DFT calculations to a specific state, which corresponds to the least excited one in our study. PFCH and BFCH absorption bands 
were observed to be $321.14,328.24,462.31$ and $312.17,314.25,448.59 \mathrm{~nm}$, respectively. As a result, only the energies of the electronic transitions $S_{0} \rightarrow S_{1}$ (absorption) and $S_{1 * \rightarrow} S_{0^{*}}$ (emission) have been calculated directly. They assumed that long-range correction has been required at the very least for the TD-DFT method, the 6-311G basis set, and the CAM-B3LYP functional level analysis of these dye compounds.

\section{Photovoltaic Properties}

The photovoltaic capabilities of DSSCs based on $\mathrm{PFCH}$ and $\mathrm{BFCH}$ were investigated under simulated AM 1.5G irradiation $\left(100 \mathrm{~mW} \mathrm{~cm}^{-2}\right)$. Fig.5 depicts the J-V plots of the DSSCs with $\mathrm{PFCH}$ and $\mathrm{BFCH}$ as aggressive dyes. In the order $\mathrm{PFCH}>\mathrm{BFCH}$, the DSSCs had higher current density and a larger area under the J-V curve. The PFCH and BFCH adsorbed concentrations are $5.22 \times 10^{-7}$ and $5.13 \times 10^{-7} \mathrm{~mol} \mathrm{~cm}^{-2}$, respectively. The lower quantity of dye loading in BFCH compared to PFCH might be ascribed to molecular structure. Table 2 and Fig.5 show that both PFCH and BFCH sensitizers have high short-circuit current (Jsc) values of 13.18 and $12.23 \mathrm{~mA} / \mathrm{cm}^{-2}$, respectively. The assessment of incident photon-to-current conversion efficiency and current voltage characteristic curves was utilized to explore the association between the dye and photovoltaic efficiency. The absorption spectral coverage benefits the DSSCs' light-harvesting capability. Figure 6 depicts the incident photon-current transfer efficiencies (IPCEs) for these dyes in DSSCs. The IPCEs of alkyl chains of varying length and composition are used to rationalize their effects on cell efficiency [43-46]. It should be mentioned that the optimal monochromatic light conversion efficiency and IPCEs for the title dye compounds were found to be between 350 and $800 \mathrm{~nm}$. BFCH will have the same initial response wavelength as $\mathrm{PFCH}$, but the response sideband changes to around $800 \mathrm{~nm}$. Furthermore, the highest monochromatic optical conversion efficiency was higher than that of $\mathrm{BFCH}$, with IPCEs of 58 and 64\%, accordingly, for BFCH and PFCH. The inclusion of BFCH and $\mathrm{PFCH}$ increased the potential energy of intramolecular electron transport, which correlated to the previously reported UV-vis absorption spectrum. 


\section{Electrochemical and electronic Properties}

Cyclic voltammetry was used to measure the molecular orbital energy levels of PFCH and $\mathrm{BFCH}$, which are depicted in Fig.7 and Table 3. The highest occupied molecular orbitals of $\mathrm{PFCH}$ and $\mathrm{BFCH}$ are 1.81 and $1.34 \mathrm{eV}$, respectively, according to respective $1^{\text {st }}$ oxidation potentials. This is owing to the fact that the HOMO level is determined by the donor component. Given that all of the dyes have a significantly higher potential than the redox pair, it's also suggested that a driving force is used to provide effective ground state regeneration for the oxidized dyes from surrounding ions following electron injection. Similarly, PFCH and BFCH have the lowest vacant molecular orbitals at -1.93 and $-1.78 \mathrm{eV}$, correspondingly. The band gap energies for PFCH and BFCH have also been observed to be 3.74 and $3.12 \mathrm{eV}$, respectively. As a result, the lowest unoccupied molecular orbitals levels of $\mathrm{PFCH}$ and $\mathrm{BFCH}$ are excessively negative than the $\mathrm{TiO}_{2}$ electrode's conduction band, which would be adequate and provide the appropriate thermodynamic driving force for electron injection from the dye to the titanium oxide conduction band. In addition, the PFCH and BFCH highest occupied molecular orbitals levels are excessive positive than the redox potential of the iodine/iodide electrolyte, supporting the regenerating of oxidized dyes. In order to gain support for absorption, the $\pi$-conjugated bridge actually isolates the donor group from the acceptor, leading to better electron injection into the titanium oxide conduction band. This is attributable to the fact that in the ground state, the electronic density is placed at the highest occupied molecular orbitals level of the donor group, and with visible exposure, this density is shifted to the acceptor group's vacant molecular orbitals level. This suggests that following light absorption, the electron transfers from the donor to the acceptor. The PFCH and BFCH highest occupied molecular orbitals are spread over donor areas, while the least occupied molecular orbitals are scattered over $\pi$-spacer and acceptor regions, showing that electrons are transported from donor to acceptor components in the present study (Fig.8). Furthermore, Table 4 summarizes the associated excitation energy, oscillator power, dipole moment, and transition character for both dye compounds. The lowest absorption, which corresponds to the HOMO $\rightarrow$ LUMO transition with ICT character, decreases in energy as the length of the furan chain increases. This can be demonstrated clearly by a reduction in the HOMO $\rightarrow$ LUMO energy difference. The lowest absorption band in the visible light field 
comprises only one electronic transition, whereas other absorption bands have several electronic transitions. Higher excitations are related to the representations of local $\pi \rightarrow \pi^{*}$ transformations or a combination of ICT and $\pi \rightarrow \pi^{*}$ characters. Furthermore, oscillator intensity (f), $E^{*}$ dye, $\Delta \mathrm{G}_{\text {inject }}$, and $\mathrm{V}_{\mathrm{oc}}$ values suggest that $\pi$-conjugation through the $\pi$-spacer is greater for both dye compounds, and this value is expressed in the measured values of LHE, which defines the photocurrent reaction of the DSSC [47 and 48]. This means that these dyes have a high ability to harvest solar energy and have high photocurrent responses. Depending on the donor group donating, the vertical excited energy of PFCH and BFCH increased. It has been observed that the higher the vertical excitation energy, the greater the conjugation of the donor group of phenothiazine and dibenzofuran. The light-harvesting efficiency (LHE) of the dye-sensitized $\mathrm{TiO}_{2}$ layer influences the efficiency of a device that transforms solar power to electric efficiency. Increased LHE values improve the DSSC's light-capture capabilities and efficiency owing to increased oscillator strength. The vertically stimulated energy of PFCH and BFCH processes is progressively being contributed by the donor group. Table 4 shows that $\Delta \mathrm{G}^{\text {inject }}$ was negative for $\mathrm{PFCH}$ and $\mathrm{BFCH}$, suggesting that the electron injection activity is spontaneous and that the excited state is positioned above the titanium oxide conduction band edge, offering a suitable environment for electron injection. These characteristics are appropriate for potentially efficient electron injection.

\section{Frontier molecular orbital analysis}

MEP images of studied molecules at the B3LYP/6-311G++(d,p) calculation level are shown in Fig.9. The regions with red color appearing in MEP images are reactive parts of the dye molecules. In the molecular electrostatic potential images of $\mathrm{PFCH}$ and $\mathrm{BFCH}$, the colors blue and red show electron deficiency and stronger electron rich regions, respectively, and these dye compounds clearly exhibit the polarization effect. The molecular electrostatic potential figures features negative potential zones over electronegative atoms and positive potential zones over hydrogen atoms. In Table 5, calculated quantum chemical parameters for investigated $\mathrm{PFCH}$ and BFCH are presented as detailed. Frontier orbital energies present reliable information about electron donating abilities of molecules. It is important to note that the higher $\mathrm{E}_{\mathrm{HOMO}}$ and lower $E_{\text {LUMO }}$ energies imply the capabilities of the electron donating and electron accepting for 
the molecular systems, respectively. The molecular orbital energy of $\mathrm{E}_{\text {Hомо }}(-5.8208$ (PFCH) \& -5.3196 eV (BFCH)), ELumo (-2.1304 (PFCH) \& -2.1154 eV (BFCH)) and energy gap (3.69 eV $(\mathrm{PFCH}) \&(3.20 \mathrm{eV}))$ revealed that the examined dye molecule exhibited considerable chemical reactivity, polarizability, and acceptable DSSCs applications. Chemical hardness [49] is reported as the resistance against electron cloud polarization of chemical systems. According to Hard and Soft Acid Base Principle (HSAB) [50] of Pearson, "hard acids prefer the binding to hard bases and soft acids prefer the binding to soft bases." In the hard and soft classification of the mentioned scientist, it is seen that hard chemical species have high energy gap and low polarizability values. For soft ones, the opposite is the case. According to the Maximum Hardness Principle [51], "there appears to be a natural norm that molecules organize themselves to be as hard as possible." In the light of this information, it is easy to predict that the hardness is a measure of the stability. The inverse relation between hardness and polarizability has been illuminated by Ghanty and Ghosh [52] and they reported that softness is proportional to the cube root of the polarizability. Minimum Polarizability Principle [53] states that stable states should have low polarizability values. According to Minimum Electrophilicity Principle that its foundations were laid by Chamorro, Chattaraj and Fuentealba [54], in a stable state, electrophilicity is minimized. Recently, Szentpaly and Kaya [55] investigated the limitations and validity of Minimum Electrophilicity Principle and presented new theorems and guiding rules about the topic. In this study, in the light of Maximum Hardness and Minimum Electrophilicity Principles, it can be said that PFCH looks more stable compared to BFCH. All of the abovementioned results clearly shown that $\mathrm{PFCH}$ and $\mathrm{BFCH}$ could be implemented in DSSCs applications.

\section{Geometrical properties analysis}

The optimized geometry at DFT/B3LYP with the 6-311G++ (d,p) basis set was obtained using the preoptimized geometry at the Hartree-Fock level. Figure 10 depicts the optimized structure of atom numbering. The bond length of $\mathrm{C}(1)-\mathrm{C}(2), \mathrm{C} 1-\mathrm{O} 3, \mathrm{~N} 4-\mathrm{N} 5, \mathrm{~N} 5=\mathrm{C} 8, \mathrm{C} 8-\mathrm{C} 9, \mathrm{C} 9$ O41, C12-O41, C2-C6, C24-N25, N25-C26, C17-S18, S19-C19, C6 झN7, C8-H30, and N4-H29 having, $1.51,1.21,1.36,1.30,1.45,1.40,1.41,1.44,1.41,1.42,1.74,1.75,1.15,1.11$ and 1.03 $\AA$, respectively. The bond angles are C19-S18-C17, C24-N25-C26, C12-O41-C9, O41-C9-C8, 
C9-C8-N5, C2-C1-N4 and C1-C2-C6 for 104.1, 125.2, 108.1, 113.0, 130.4, 166.6 and 112.6 correspondingly. The dihedral angle of C10-C9-C8-N5, C8-N5-N4-C1, C1-C2-C6-N7, C16C15-C14-C12, C20-C9-S8-C17 and C24-N25-C26-C13 is 0.3, -179.9, -179.2, 179.6, 174.5 and $176.3^{\circ}$, respectively. The bond length of C1-C2, C2-C24, N4-N5, C6-C7, C7-O39, C10-O39, $\mathrm{C} 19-\mathrm{C} 10, \mathrm{C} 15-\mathrm{O} 11, \mathrm{C} 12-\mathrm{O} 11, \mathrm{C} 1=\mathrm{O} 3, \mathrm{C} 13-\mathrm{C} 14, \mathrm{C} 24 \equiv \mathrm{N} 25, \mathrm{~N} 4-\mathrm{H} 28, \mathrm{C} 2-\mathrm{H} 26$, and $\mathrm{C} 2-\mathrm{H} 27$ are $1.53,1.46,1.38,144,1.31,1.39,1.40,1.45,1.41,1.40,1.24,1.46,1.17,1.02,1.10$ and $1.09 \AA$, respectively.C7-C8-C9, C15-O11-C12, C10-O39-C7, C7-C6-N5, C6-N5-N4, N4-C1-C2, C1-C2C24 having 107.9, 105.9, 107.7, 130.4, 119.5, 115.2 and 112.8 , respectively. C8-C7-C6-N5, C10-O39-C7-C6, N5-N4-C1-C2, O11-C12-C19-C10, C21-C20-C15-O11, C16-C13-C14-C15 having $180.0,179.9,0.3,-179.9,0.5,-180.0$ and $-179.6^{\circ}$ respectively. The geometrical parameters indicate that planar configuration has a minor effect on electron delocalization and intramolecular charge transfer along dye molecules. Subsequently, it is reasonable to assume that advancements in molecular geometry will affect the electronic properties of dyes and also their performance in applications.

\section{Natural bond orbital analysis}

Intramolecular electron delocalization due to hyper conjugation is very important for the stabilization of a molecule [56]. Natural bond orbitals can be used as an ideal method for the evaluation of these types of interactions. NBO 3.1 suite associated with Gaussian 09W program was used to perform these calculations [57]. The orbital occupancy and delocalization energy data helps to analyze the different electron shifting. Both bonding and anti-bonding orbitals for $\mathrm{PFCH}$ and $\mathrm{BFCH}$ can give details in this part by transfer of electrons having suitable occupancies, from bonding, lone pairs and anti-bonding orbitals to anti-bonding orbitals with absorbing some energy (refer Tables S1 and S2). The strong intra-molecular hyper conjugative interactions (Table S3) due to lone pair atoms are from $\mathrm{O} 3 \rightarrow(\mathrm{C} 1-\mathrm{N} 4), \mathrm{N} 4 \rightarrow(\mathrm{C} 1-\mathrm{O} 3, \mathrm{~N} 5-\mathrm{C} 8)$, $\mathrm{N} 25 \rightarrow(\mathrm{C} 13-\mathrm{C} 26, \mathrm{C} 23-\mathrm{C} 24)$ and $\mathrm{O} 41 \rightarrow(\mathrm{C} 9-\mathrm{C} 10, \mathrm{C} 11-\mathrm{C} 12)$ with energies, 24.38, 54.25, 28.56, $34.04,31.88,23.54,25.62 \mathrm{kcal} / \mathrm{mol}$ for $\mathrm{PFCH}$ and $\mathrm{O} 3 \rightarrow(\mathrm{C} 1-\mathrm{C} 2, \mathrm{C} 1-\mathrm{N} 4), \mathrm{N} 4 \rightarrow(\mathrm{C} 1-\mathrm{O} 3, \mathrm{~N} 5-\mathrm{C} 6)$, $\mathrm{O} 11 \rightarrow(\mathrm{C} 12-\mathrm{C} 13, \mathrm{C} 14-\mathrm{C} 15)$ and $\mathrm{O} 39 \rightarrow(\mathrm{C} 7-\mathrm{C} 8, \mathrm{C} 9-\mathrm{C} 10)$ with energies, 21.44, 23.82, 57.43, $31.77,22.87,21.48,22.10,23.63 \mathrm{kcal} / \mathrm{mol}$ for $\mathrm{BFCH}$. 


\section{Nonlinear optical properties}

Organic materials are considered in photonic devices because of their comparable results and the ability to optimize molecules to exploit nonlinear response. Electronic delocalization is caused by $\pi$-electron results in hyperpolarizabilities through organic compounds, which occurs macroscopic objects as nonlinear sensitivities. As a result, the first step in looking for a desirable substance is to find a lead molecule with strong hyperpolarizabilities. Molecular NLO materials are currently being studied and are of great concern because new technological features are needed as electronic devices become more useful. The dipole moment (Debye), polarizability $\left(\times 10^{-23} \mathrm{esu}\right)$, first order and second order hyperpolarizabilities $\left(\times 10^{-30}\right.$ esu and $\times 10^{-37}$ esu $)$ of PFCH/BFCH are 8.6457/10.0400, 4.710/3.936, 52.451/14.783 and -63.279/-36.282.

\section{Vibrational analysis}

The vibrational spectra of the dye compounds for scrutiny is calculated theoretically for optimized geometrical structures. The determined vibrational spectra were analyzed using the most significant set of frequencies for functional groups and structural components found in organic compounds [58]. Figures S2 and S3 depict the experimental and scaled vibrational spectra. Aromatic $\mathrm{CH}$ stretching vibrations are frequently observed in the $3100-3000 \mathrm{~cm}^{-1}$ regions [40], and the title dyes $\mathrm{PFCH}$ and $\mathrm{BFCH}$ both have $12 \mathrm{CH}$ stretching vibrations. The $\mathrm{CH}$ stretching vibration frequencies observed at 3152, 3122, 3088, 3048, 3028, 2988, 2872, $2851 \mathrm{~cm}^{-1}$ (PFCH) and 3202, 3096, 3069, 3052, 3046, 2954, $2918 \mathrm{~cm}^{-1}$ (BFCH) have excellent consistency with theoretical wavenumbers at 3145-2845 and 3208-2916 for BFCH. The CCH in plane bending vibration observed FT-IR bands at 1301, 1294, 1292, 1224, 1042 for PFCH and 1333, 1301, 1236, 1158, 1149 for BFCH, with computed peaks at 1305, 1298, 1288, 1227, 1046 $(\mathrm{PFCH})$ and 1339, 1305, 1237, 1159, $1147(\mathrm{BFCH}) . \mathrm{CCH}$ out-of-plane bending vibrations are observed at 977, 878, 844, 758, 715 for $\mathrm{PFCH}$ and 964, 918, 826, 746 for BFCH, which are well associated with calculated bands at 978, 870, 847, 761, $715(\mathrm{PFCH})$ and 966, 921, 825, 748 $(\mathrm{BFCH})$. The $\mathrm{C}-\mathrm{C}$ bond stretching vibration occurs in the regions of 1592, 1588, 1581, 1552, 1514, 1488, 1466, 1429, $1381 \mathrm{~cm}^{-1}(\mathrm{PFCH})$ and 1658, 1562, 1518, 1448, $1422 \mathrm{~cm} 1$ (BFCH), which correspond with measured modes at 1652-1248 $\mathrm{cm}^{-1}(\mathrm{PFCH})$ and 1594-1321 $\mathrm{cm}^{-1}$ $(\mathrm{BFCH})$. The computed wavenumber for CCC bending vibration is also well associated with the 
observed bands (refer Table S1 and S2). The CN stretching vibration is usually found in combination with mixed vibrations from other bands. The CN stretching bands appear at 2341 (2342), 1581 (1584), 1179 (1181), 1166 (1158) for PFCH, and 2229 (2223), 1388 (1386), 1333 (1339), 1236 (1237) for (BFCH). The NH stretching bands occur at 3503 (3512), 3356 (3354) $\mathrm{cm}^{-1}$ for $\mathrm{PFCH}$, and $3446(3452) \mathrm{cm}^{-1}$ for $\mathrm{BFCH}$, respectively and in plane bending vibrations appear at 1466 (1462), 1381 (1383) for PFCH, and 1448 (1453), 1301 (1305) cm-1 for BFCH). In addition, Out-of-plane bending vibrations for PFCH and PFCH originate at 1097 (1084), 844 (847) $\mathrm{cm}^{-1}$ and 1098 (1100), $891(884) \mathrm{cm}^{-1}$, accordingly. CCO fragment stretching modes exist at 1801 (1796) $\mathrm{cm}^{-1}$ for $\mathrm{PFCH}$ and 1575 (1578) $\mathrm{cm}^{-1}$ for $\mathrm{BFCH}$, respectively. The configuration and number of separated ring hydrogen atoms determine the position and number of $\mathrm{C}-\mathrm{H}$ inplane vibration modes, while the number of free hydrogen atoms adjacent to one another determines the position of $\mathrm{C}-\mathrm{H}$ out-of-plane deformation bands. Besides that, the C-S experimental FT-IR stretching bands appear at $1218,828 \mathrm{~cm}^{-1}$, which correspond to measured modes of 1222, $831 \mathrm{~cm}^{-1}$, respectively. The minor variations in frequencies seen for these modes are due to differences in force constants/reduced mass ratios, which are mostly influenced by the degree of mixing in between the ring and moieties groups.

The position and the number of $\mathrm{C}-\mathrm{H}$ in-plane vibration modes depend on the orientation and the number of isolated ring hydrogen atoms, whereas the position of the C-H out-of-plane deformation bands depend on the number of free hydrogen atoms adjacent to one another. Furthermore, the C-S experimental FT-IR stretching bands appear at $1218,828 \mathrm{~cm}^{-1}$, that are well associated with measured modes of $1222,831 \mathrm{~cm}^{-1}$, respectively. The small differences in frequencies seen for these modes are due to differences in force constants/reduced mass ratio largely caused by the magnitude of mixing in between ring and moieties group. The other important modes are also classified and compared to the calculated bands seen in Tables S3 and S4.

\section{NMR spectra}

Normally, isotropic chemical shifts are used to characterize organic reactive sites. In order to quantify the magnetic properties of molecules, precise molecular geometries must be predicted [55]. The ${ }^{13} \mathrm{C}$ and ${ }^{1} \mathrm{H}$ NMR spectra of the title dye molecules were recorded by using 
DMSO $\mathrm{d}_{6}$ solvent, and their images (Figs.S4, S5, S6, and S7) are presented in the supplementary material. Similarly, the chemical shifts were theoretically calculated in DMSO solvent with DFT/B3LYP function 6-311G++(d,p) basis set. Furthermore, the PFCH and BFCH NMR chemical shifts are related to calculated values. Carbonyl carbon (C1) chemical shift is found at 161.13 (162.48) and alkyl carbons C8, C6, and C2 chemical shifts are observed at 127.18 (123.53), 121.93 (119.44) and 25.54 (30.59), respectively. Furan ring carbons of C12, C9, C10, and C11 can also be found at 155.98 (155.14), 137.40 (139.95), 109.55 (101.45), and 109.54 (98.14). Phenoxazine ring carbons of C26, C24, C14, C17, C20, C22, C13, C21, C15, C16, C23 and C19 peaks have been identified at 135.19 (137.24), 131.10 (133.96), 129.47 (127.17), 127.78 (126.13), 127.73 (125.38), 127.54 (124.85), 127.23 (124.11), 127.09 (122.22), 125.65 (121.22), 121.92 (115.25), 121.88 (113.10), 114.54 (108.14). The BFCH carbonyl carbon (C1) chemical shift occurs at 162.12 (164.52), and alkyl carbons of C6, C24, and C2 arise at 127.92 (121.48), 112.61 (106.37), and 22.35 (28.32), accordingly. Furan ring carbons of C10, C7, C8, and C9 NMR peaks are also observed at 155.24 (153.58), 144.12 (148.69), 95.62 (101.41), and 92.15 (95.35). The dibenzofuran ring carbons C15, C12, C13, C14, C17, C21, C22, C18, C19, C23, C16, C20 chemical shifts to be found at 144.33 (149.73), 144.11(147.73), 133.92 (128.45), 133.48 (127.12), 128.69 (125.13), 128.48 (122.34), 126.65 (121.14), 125.48 (120.48), 125.46 (120.15), 125.42 (119.49), 112.62 (108.75), 112.65 (108.75), 112.62 (107.46). Similarly, chemical shifts for the dibenzofuran ring carbons C15, C12, C13, C14, C17, C21, C22, C18, C19, C23, C16, C20 can be found at 144.33 (149.73), 144.11(147.73), 133.92 (128.45), 133.48 (127.12), 128.69 (125.13), 128.48 (122.34), 126.65 (121.14), 125.48 (120.48), 125.46 (120.15), 125.42 (119.49), 112.62 (108.75), 112.65 (108.75), 112.62 (107.46). The calculated and observed chemical shift values of $\mathrm{PFCH}$ and $\mathrm{BFCH}$ in ${ }^{1} \mathrm{H}$ and ${ }^{13} \mathrm{C} \mathrm{NMR}$ are in strongly agree. Alkyl protons of $\mathrm{H} 30, \mathrm{H} 29, \mathrm{H} 28, \mathrm{H} 27{ }^{1} \mathrm{H}-\mathrm{NMR}$ spectra have been arise at 8.35 (8.69), 7.43 (7.64), 3.03 (2.59), 3.01 (2.09) and furan ring protons of H31, H32 can also found at 7.19 (7.12), 7.11 (7.01). Phenoxazine ring protons of H34, H38, H37, H36, H35, H39, H33, H40 are occur at 7.42 (7.52), 7.31 (7.33), 7.26 (7.29), 7.19 (7.11), 7.12 (7.04), 6.37 (6.59), 6.36 (6.37), 6.28 (6.11). The dye PFCH, alkyl protons of $\mathrm{H} 30, \mathrm{H} 29, \mathrm{H} 28, \mathrm{H} 27{ }^{1} \mathrm{H}$ NMR spectra have been observed at 8.35 (8.69), 7.43 (7.64), 3.03 (2.59), 3.01 (2.09) and furan ring protons of H31, H32 can also be found at 7.19 (7.12), 7.11 (7.01). Phenoxazine ring protons of H34, H38, H37, H36, 
H35, H39, H33, H40 occur at 7.42 (7.52), 7.31 (7.33), 7.26 (7.29), 7.19 (7.11), 7.12 (7.04), 6.37 (6.59), 6.36 (6.37), 6.28 (6.11). Similarly, dye BFCH, H29 proton ${ }^{1} \mathrm{H}-\mathrm{NMR}$ have been found at 8.66 (8.93). The calculated NMR values are well correlated with the experimental values. The calculated and experimental ${ }^{1} \mathrm{H}$ and ${ }^{13} \mathrm{C}$ NMR peaks revealed the molecular structure of $\mathrm{PFCH}$ and $\mathrm{BFCH}$.

\section{Conclusion}

(Z)-N-((5-(10H-phenothiazin-2-yl)furan-2-yl)methylene)-2-cyanoacetohydrazide ( $\mathrm{PFCH})$ and (Z)-2-cyano-N'-((5-(dibenzo[b,d]furan-4-yl)furan-2-yl)methylene)acetohydrazide (BFCH) dye molecules synthesized and NMR, FT-IR, and UV-Vis studies would be used to characterize all dye molecule. The molecular geometrical parameters of the dyes under examination revealed a significant conjugation effect, which will aid in the transfer of an excited electron from the donor to acceptor. The molar extinction coefficients of PFCH and BFCH are 21448 and 20796 $\mathrm{M}^{-1} \mathrm{~cm}^{-1}$, respectively, which might indicate their ability to harvest light. The photophysical analysis shows that the donor group is significant in improving the optoelectronic characteristics and performance of DSSC devices. The monochromatic optical conversion efficiency of PFCH found higher than that of $\mathrm{BFCH}$, with IPCEs of 58 and $64 \%$ for $\mathrm{BFCH}$ and $\mathrm{PFCH}$, respectively. The remarkable solar energy efficiency suggested that the dyes injected very efficient electrons into the titanium oxide conduction band. The inclusion of an acceptor improves ICT and $\mathrm{J}_{\mathrm{SC}}$ enhanced drawing ability. The quantum chemical calculation results of $\mathrm{PFCH}$ and $\mathrm{BFCH}$ revealed that the electron transfer abilities of the D- $\pi$-A device were acceptable. The NBO and NLO values additionally suggest that the title compounds are suitable for usage in DSSCs devices. The experimental and theoretical values results strongly indicate that the possibilities for using organic dye photosensitizers in DSSCs are promising, both in case of solar conversion efficiency and the potential of low-cost manufacture.

\section{Acknowledgements}

The authors would like to express their gratitude to Gandhigram Rural University and SAIF Chennai for providing spectral and electrochemical resources.

\section{Funding}

We have received no funding for our exploratory efforts. 


\section{Conflict of Interest}

The authors confirm that they had no conflicts of interest in relation to this research work.

\section{Author contribution}

K. Periyasamy: Experimental, DFT studies and manuscript writing

P. Sakthivel: Supervision, Manuscript preparation and data analysis

G.Venkatesh: Manuscript draft correction and Method development and standardization

P.M. Anbarasan: Software and electrochemical data analysis

P.Vennila: Validation curation of data and method development

Y.Sheena Mary: Conceiving of the problem

S.Kaya: FMO calculation

Sultan Erkan: Manuscript draft correction

\section{Data availability}

The Supplementary Information Files include additional materials.

\section{Code availability}

No new codes have been created. Existing codes were utilized and quoted correctly.

\section{References}

1. Yella A, Lee HW, Tsao HN, Yi C, Chandiran AK, Nazeeruddin MK, Diau EWD, Yeh CY, Zakeeruddin SM, Grätzel M, (2011) Porphyrin-sensitized solar cells with cobalt (II/III)-based redox electrolyte exceed 12 percent efficiency. Science, 334:629-634.

2. Hemavathi B, Jayadev V, Praveen, Ramamurthy C, Ranjith Krishna Pai, Narayanan Unni KN, Ahipa TN, Soman S, Geetha Balakrishna R, (2019) Variation of the donor and acceptor in $\mathrm{D}-\mathrm{A}-\pi-\mathrm{A}$ based cyanopyridine dyes and its effect on dye sensitized solar cells. New J. Chem. 43:15673-15680.

3. Saravana Kumaran T, Prakasam A, Anbarasan PM, Vennila P, Venkatesh G, Parveen Banu S, Sheena Mary Y, (2021). New Phenoxazine-Based Organic Dyes with Various Acceptors for Dye-Sensitized Solar Cells: Synthesis, Characterization, DSSCs Fabrications and DFT Study, J. Comput. Biophys. Chem. 20:1-12.

4. Mathew S, Yella A, Gao P, Humphry-Baker R, Curchod BF, Ashari-Astani N, Tavernelli I, Rothlisberger U, Nazeeruddin MK, Grätzel M, (2014) Dye-sensitized solar cells with 
$13 \%$ efficiency achieved through the molecular engineering of porphyrin sensitizers. Nat.Chem. 6:242-247.

5. Yella A, Mai CL, Zakeeruddin CM, Chang SN, Hsieh CH, Yeh CY, Grätzel M, (2014) Angew. Chem. 53:3017-3021.

6. Amogne NY, Ayele DW, Tsigie YA, (2020) Recent advances in anthocyanin dyes extracted from plants for dye sensitized solar cell. Mater. Renew. Sustain. Energy. 9:23.

7. Zhang X, Xu Y, Giordano F, Schreier M, Pellet N, Hu Y, Yi C, Robertson N, Hua J, Zakeeruddin SM, Tian H, Grätzel M (2016), J. Am. Chem. Soc. 138:10742-10745.

8. Iqbal Z, Wu WQ, Huang ZS, Wang L, Kuang DB, Meier H, Cao D, (2016) Trilateral $\pi$ conjugation extensions of phenothiazine based dyes enhance the photovoltaic performance of the dye-sensitized solar cells. Dyes Pigm. 124:63-71.

9. Nagatoshi Koumura, Zhong-Sheng Wang, Shogo Mori, Masanori Miyashita, Eiji Suzuki, Kohjiro Hara (2008) Alkyl-Functionalized Organic Dyes for Efficient Molecular Photovoltaic. J. Am. Chem. Soc.128:14256-1425

10. K. R. Justin Thomas, Neha Kapoor, Chuan-Pei Lee, Kuo-Chuan Ho (2012) Organic Dyes Containing Pyrenylamine-Based Cascade Donor Systems with Different Aromatic $\pi$ Linkers for Dye-Sensitized Solar Cells: Optical, Electrochemical, and Device Characteristics. Chemistry-An Asian Journal, 7 (4):738-750

11. Lee JK, Yang M (2011) Review Progress in Light Harvesting and Charge Injection of Dye Sensitized Solar Cells. Mater. Sci. Eng. B, 176:1142-1160.

12. Liu B, Zhu W, Zhang Q, Wu W, Xu M, Ning Z, Xie Y, Tian H (2009) Conveniently synthesized isophorone dyes for high efficiency dye-sensitized solar cells: Tuning photovoltaic performance by structural modification of donor group in donor- $\pi$-acceptor system. Chem Commun, 2:1766-1768.

13. Horiuchi T, Miura H, Sumioka K, Uchida S (2004) High efficiency of dye-sensitized solar cells based on metal-free indoline dyes. J Am Chem Soc,126: 12218-12219

14. Revoju S, Biswas S, Eliasson B, Sharma GD (2018) Asymmetric triphenylaminephenothiazine based small molecules with varying terminal acceptors for solution processed bulk-heterojunction organic solar cells. Phys. Chem. Chem. Phys. 20: 6390640. 
15. Slodek A, Zych D, Szafraniec-Gorol G, Gnida P, Vasylieva M, Schab-Balcerzak E (2020) Investigations of New Phenothiazine-Based Compounds for Dye-Sensitized Solar Cells with Theoretical Insight. Materials, 13(10):2292.

16. Bourass M, Benjelloun AT, Benzakour M, Mcharfi M, Jhilal F, Serein-Spirau F, Sotiropoulos JM, Bouachrine M (2017) DFT/TD-DFT characterization of conjugational electronic structures and spectral properties of materials based on thieno[3,2b][1]benzothiophene for organic photovoltaic and solar cell applications. J. Saudi Chem. Soc. 21, 563-574.

17. Khayer K, Haque T (2020) Density Functional Theory Calculation on the Structural, Electronic, and Optical Properties of Fluorene-Based Azo Compounds. ACS Omega, 5:4507-4531.

18. Slodek A, Zych D, Golba S, Zimosz S, Gnida P, Schab-Balcerzak E (2019) Impact of the donor structure in new $\mathrm{D}-\pi-\mathrm{A}$ systems based on indolo[3,2,1-jk]carbazoles on their thermal, electrochemical, optoelectronic and luminescence properties. J. Mater. Chem. C, 7:5830-5840.

19. Belić J, van Beek B, Menzel JP, Buda F, Visscher L (2020) Systematic Computational Design and Optimization of Light Absorbing Dyes, J. Phys. Chem. A 124:6380-6388.

20. Abdullah G, Al-Sehemi, Shuhrah Ali S, Allami, Abul Kalam (2020) Design and synthesis of organic dyes with various donor groups: promising dyes for dye-sensitized solar cells. Bull. Mater. Sci. 43:224.

21. Park JM, Jung CY, Wang Y, Choi HD, Park SJ, Ou P, Jang WD, Jaung JY (2019) Effect of additional phenothiazine donor and thiophene $\pi$-bridge on photovoltaic performance of quinoxaline cored photosensitizers.Dyes Pigms. 170:107568.

22. Huang ZS, Meier H, Cao D (2016) Phenothiazine-based dyes for efficient dye-sensitized solar cells. J. Mater. Chem.C, 4:2404-2426.

23. Buene AF, Uggerud N, Economopoulos SP, Gautun OR, Hoff BH (2018) Dyes Pigms. 151:263-271.

24. Ahmad S, Guillen E, Kavan L, Grätzel M, Nazeeruddin MK (2013) Metal free sensitizer and catalyst for dye sensitized solar cells. Energy Environ. Sci. 6:3439-3466. 
25. Zhou H, Ji JM, Kang SH, Kim MS, Lee HS, Kim CH, Kim HK (2019) Molecular design and synthesis of $\mathrm{D}-\pi-\mathrm{A}$ structured porphyrin dyes with various acceptor units for dyesensitized solar cells. J. Mater. Chem. C, 7:2843-2852.

26. Velu S, Muniyasamy H, Ayyanar S, Maniarasu S, Veerappan G, Sepperumal M (2019) synthesis of organic sensitizers containing carbazole and triphenylamine $\pi$-bridged moiety for dye-sensitized solar cells. J. Iran. Chem. Soc. 16:1923-1937.

27. Kim SH, Kim HW, Sakong C, Namgoong J, Park SW, Ko MK, Hyuk Lee C, Lee WI, Kim JP (2011) Effect of Five-Membered Heteroaromatic Linkers to the Performance of Phenothiazine-Based Dye-Sensitized Solar Cells. Org. Lett. 13:5784-5787.

28. M.J. Frisch, G.W. Trucks, H.B. Schlegel, G.E. Scuseria, M.A. Robb, J.R. Cheeseman, J.A. Montgomery Jr., T. Vreven, K.N. Kudin, J.C. Burant, J.M. Millam, S.S. Iyengar, J. Tomasi, V. Barone, B. Mennucci, M. Cossi, G. Scalmani, N. Rega, G.A. Petersson, H. Nakatsuji, M. Hada, M. Ehara, K. Toyota, R. Fukuda, J. Asegawa, M. Ishida, T. Nakajima, Y. Honda, O. Kitao, H. Nakai, M. Klene, X. Li, J.E. Knox, H.P. Hratchian, J.B. Cross, C. Adamo, J. Jaramillo, R. Gomperts, R.E. Stratmann, O. Yazyev, A.J. Austin, R. Cammi, C. Pomelli, J.W. Ochterski, P.Y. Ayala, K. Morokuma, G.A. Voth, P. Salvador, J.J. Dannenberg, V.G. Zakrzewski, S. Dapprich, A.D. Daniels, M.C. Strain, O. Farkas, D.K. Malick, A.D. Rabuck, K. Raghavachari, J.B. Foresman, J.V. Ortiz, Q. Cui, A.G. Baboul, S. Clifford, J. Ioslowski, B.B. Stefanov, G. Liu, A. Liashenko, P. Piskorz, I. Komaromi, R.L. Martin, D.J. Fox, T. Keith, M.A. AlLaham, C.Y. Peng, A. Nanayakkara, M. Challacombe, P.M.W. Gill, B. Johnson, W. Chen, M.W. Wong, C. Gonzalez, J.A. Pople (2009) Gaussian 03, Revision E.01, Gaussian Inc,. Pittsburgh. B.A. 2000. Walliford CT, 121:150-166.

29. Scott AP, Radom L (1996) Harmonic Vibrational Frequencies: An Evaluation of Hartree-Fock, Moller-Plesset, Quadratic Configuration Interaction, Density Functional Theory, and Semiempirical Scale Factors. J. Phys. Chem. 100:16502-16513.

30. Islam N, Kaya S (2018) Conceptual Density Functional Theory and Its Application in the Chemical Domain CRC Press.

31. Koopmans T (1934) über Die Zuordnung Von Wellenfunktionen Und Eigenwerten Zu Den Einzelnen Elektronen Eines Atoms. Physica 1:104-113. 
32. Pearson RG (1999) Maximum Chemical and Physical Hardness. J. Chem. Educ. 76:267

33. Gazquez JL, Cedillo A, Vela A (2007) Electrodonating and electroaccepting powers. J. Phys. Chem. A, 111:1966-1970.

34. Palanisamy SP, Maheswaran G, Geetha Selvarani A, Kamal C, Venkatesh G (2018) Ricinus communis - A green extract for the improvement of anti-corrosion and mechanical properties of reinforcing steel in concrete in chloride media. J. Build. Eng. 19:376-383.

35. Saravana Kumaran, T, Prakasam A,Venkatesh G, Kamal C, Sheena Mary Y, Parveen Banu S, Vennila P, Shyma Mary Y (2020) Synthesis, spectral characterizations, molecular geometries and electronic properties of phenothiazine based organic dyes for dye-sensitized solar cells. Zeitschrift für Physikalische Chemie, https://doi.org/10.1515/zpch-2020-1732

36. Zanjanchi F., Beheshtian J (2018) Natural pigments in dye-sensitized solar cell (DSSC): A DFT-TDDFT study. J. Iran. Chem. Soc.16:795-805. doi: 10.1007/s13738-018-1561-2.

37. Saravana Kumaran T, Prakasam A, Vennila P, Parveen Banu S, Venkatesh G (2021) New Carbazole-Based Organic Dyes with Various Acceptors for Dye-Sensitized Solar Cells: Synthesis, Characterization, DSSCs Fabrications and DFT Study. Asian J. Chem. 33:1541-1550.

38. Harikrishnan M, Sadhasivam V, Siva A, Anandan S, Subbiah V, Murugesan S (2019) Energy Level Tuning of Novel Star-Shaped D- $\pi-D-A-B a s e d$ Metal-Free Organic Dyes for Solar Cell Application. J. Phys. Chem. C, 123:21959-21968.

39. Sun C, Li Y, Qi D, Li H (2016) Optical and electrical properties of purpurin and alizarin complexone as sensitizers for dye-sensitized solar cells. J Mater Sci: Mater Electron. 27:8027-8039.

40. Periyasamy K, Sakthivel P, Vennila P, Anbarasan PM, Venkatesh G, Sheena Mary Y (2021) Novel D- $\pi$-A phenothiazine and dibenzofuran organic dyes with simple structures for efficient dye-sensitized solar cells. J. Photochem. Photobiol. A, 413:113269.

41. M. Batzill, Fundamental aspects of surface engineering of transition metal oxide photocatalysts. Energy Environm. Sci. 4, 3275-3286 (2011). 
42. J.Pan, G.Liu, G.Q. Lu, H.M.Cheng, On the true photoreactivity order of $\{001\},\{010\}$ and $\{101\}$ facets of anatase $\mathrm{TiO}_{2}$ crystals. Angew. Chem., Int. Ed. 50, 2133-2137 (2011)

43. We Li Zhang, Xichuan Yang, Weihan Wang, Gagik G. Gurzadyan, Jiajia Li, Xiaoxin Li, Jincheng An, Ze Yu, Haoxin Wang, Bin Cai, Anders Hagfeldt, Licheng Sun 13.6\% Efficient Organic Dye-Sensitized Solar Cells by Minimizing Energy Losses of the Excited State (2019) ACS Energy Lett. 4:943-95

44. Kaiwen Zeng, Yingying Chen, Wei-Hong Zhu, He Tian, Yongshu Xie (2020) Efficient Solar Cells Based on Concerted Companion Dyes Containing Two Complementary Components: An Alternative Approach for Cosensitization. J. Am. Chem. Soc. 142:51545161.

45. Jung-Min Ji, Haoran Zhou, Hwan Kyu Kim (2018) Rational design criteria for D- $\pi-A$ structured organic and porphyrin sensitizers for highly efficient dye-sensitized solar cells. J. Mater. Chem. A, 6:14518-14545.

46. Haoran Zhou, Jung-Min Ji, Sung Ho Kang, Min Su Kim, Hyun Seok Lee, Chul Hoon Kim, Hwan Kyu Kim (2019) Molecular design and synthesis of D- $\pi-A$ structured porphyrin dyes with various acceptor units for dye-sensitized solar cells. J. Mater. Chem. C, 7:2843-2852.

47. Juma JM, Ali S, Vuai H, Babu NS (2019) TD-DFT Investigations on Optoelectronic Properties of Fluorescein Dye Derivatives in Dye-Sensitized Solar Cells (DSSCs). Int.J. Photoenergy, 4616198.

48. Athira M. John, Renjith Thomas, Sreeja $\quad$ P. Balakrishnan, Nabil Al-Zaqri, Ali Alsalme and Ismail Warad, Diazo-pyrazole analogues as photosensitizers in dye sensitised solar cells: tuning for a better photovoltaic efficiency using a new modelling strategy using experimental and computational data, Zeitschrift für Physikalische Chemie, doi.org/10.1515/zpch-2020-1722

49. Venkatesh G, Kamal C, Vennila P, Govindaraju M, Sheena Mary Y, Stevan Armakovic, Sanja J. Armakovic, Kaya S, Yohannan Panicker C (2018) Molecular dynamic simulations, ALIE surface, Fukui functions geometrical, molecular docking and vibrational spectra studies of tetra chloro $p$ and $m$-xylene. J.Mol.Struct. 1171:253-267.

50. Pearson RG (1963) Hard and Soft Acids and Bases. J. Am. Chem. Soc. 85:3533-3539. 
51. Saha R, Pan S, Chattaraj PK (2016) molecules Statistical Significance of the Maximum Hardness Principle Applied to Some Selected Chemical Reactions. Molecules, 21:1477.

52. Tapan K. Ghanty, Swapan K. Ghosh (2000) Molecular Hardness, Polarizability and Valency Variation of Formamide and Thioformamide on Internal Rotation: A Density Functional Study. J. Phys. Chem. A, 104:2975-2979

53. Chattaraj PK, Sarkar, U, Roy DR (2006) Electrophilicity index. Chem. Rev.106:20652091.

54. E. Chamorro, P.K. Chattaraj, P. Fuentealba (2003) Variation of the Electrophilicity Index along the Reaction Path. J. Phys. Chem. A, 107:7068-7072.

55. László von Szentpály, Savaş Kaya, Nihat Karakuş. Why and When Is Electrophilicity Minimized? New Theorems and Guiding Rules (2020). Am. J. Phys. Chem., 124:1089710908.

56. Vennila P, Govindaraju M, Venkatesh G, Kamal C (2016) Molecular structure, vibrational spectral assignments (FT-IR and FT-RAMAN), NMR, NBO, HOMO-LUMO and NLO properties of O-methoxybenzaldehyde based on DFT calculations, J. Mol. Struct. 1111:151

57. Weinhold F, Landis C R, Glendening ED (2016) What is NBO analysis and how is it useful? Int. Rev. in Phys. Chem. 35:399.

58. Venkatesh G, Govindaraju M, Kamal C, Vennila P, Kaya S (2017) Structural, electronic and optical properties of 2,5 dichloro-p-xylene: experimental and theoretical calculations using DFT method, RSC Adv. 7:1401 


\section{Figure caption}

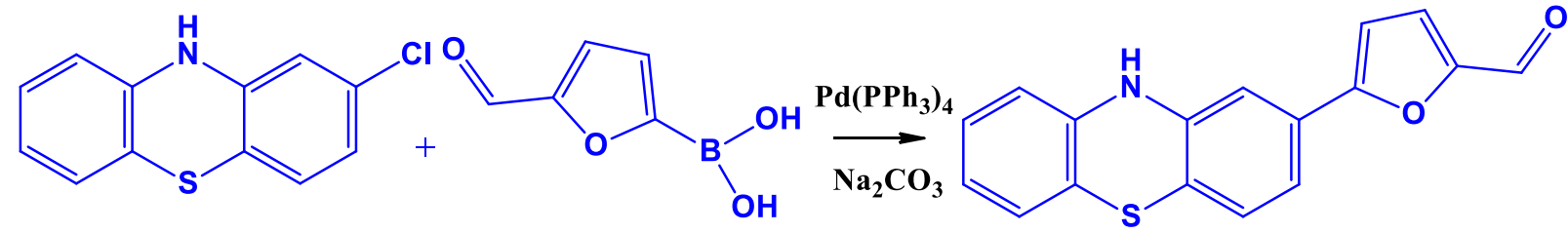

2-Chlorophenothiazine (5-formylf uran-2-yl) boronic acid<smiles>N#CCC(=O)N/N=C\c1ccc(-c2ccc3c(c2)Nc2ccccc2S3)o1</smiles>

5-(10H-phenothiazin-2-yl)f uran-2carbaldehyde

EtOH

Acetic acid/

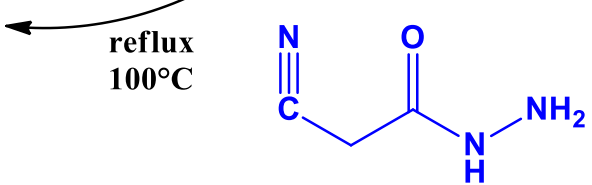

2-cyanoacetohydrazide

(Z)-N'-((5-(10H-phenothiazin-2-yl)f uran-2-yl)methylene)-2cyanoacetohydrazide<smiles>Brc1cccc2c1oc1ccccc12</smiles>

4-bromodibenzofuran

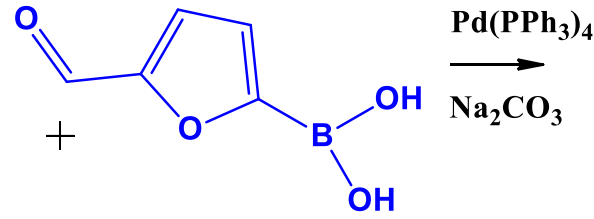

(5-formylf uran-2-yl)boronic acid

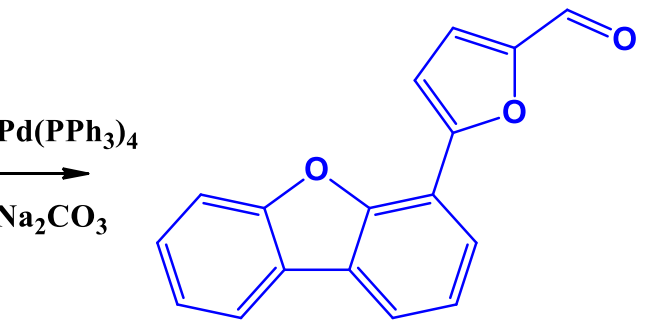

5-(dibenzo $[b, d]$ furan-4-yl) furan-2-carbaldehyde<smiles>N#CCC(=O)N/N=C\c1ccc(-c2cccc3c2oc2ccccc23)o1</smiles>

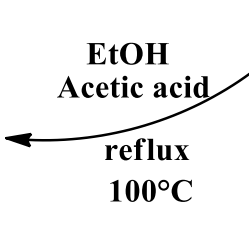

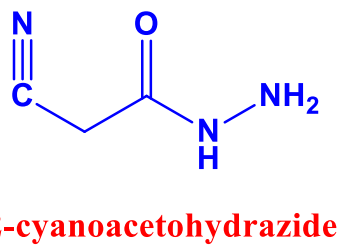

(Z)-2-cyano- $N$ '-((5-(dibenzo[b,d]f uran-4-yl)f uran-2yl)methylene)acetohydrazide

\section{Fig.1 Synthesis of PFCH and BFCH organic dyes}




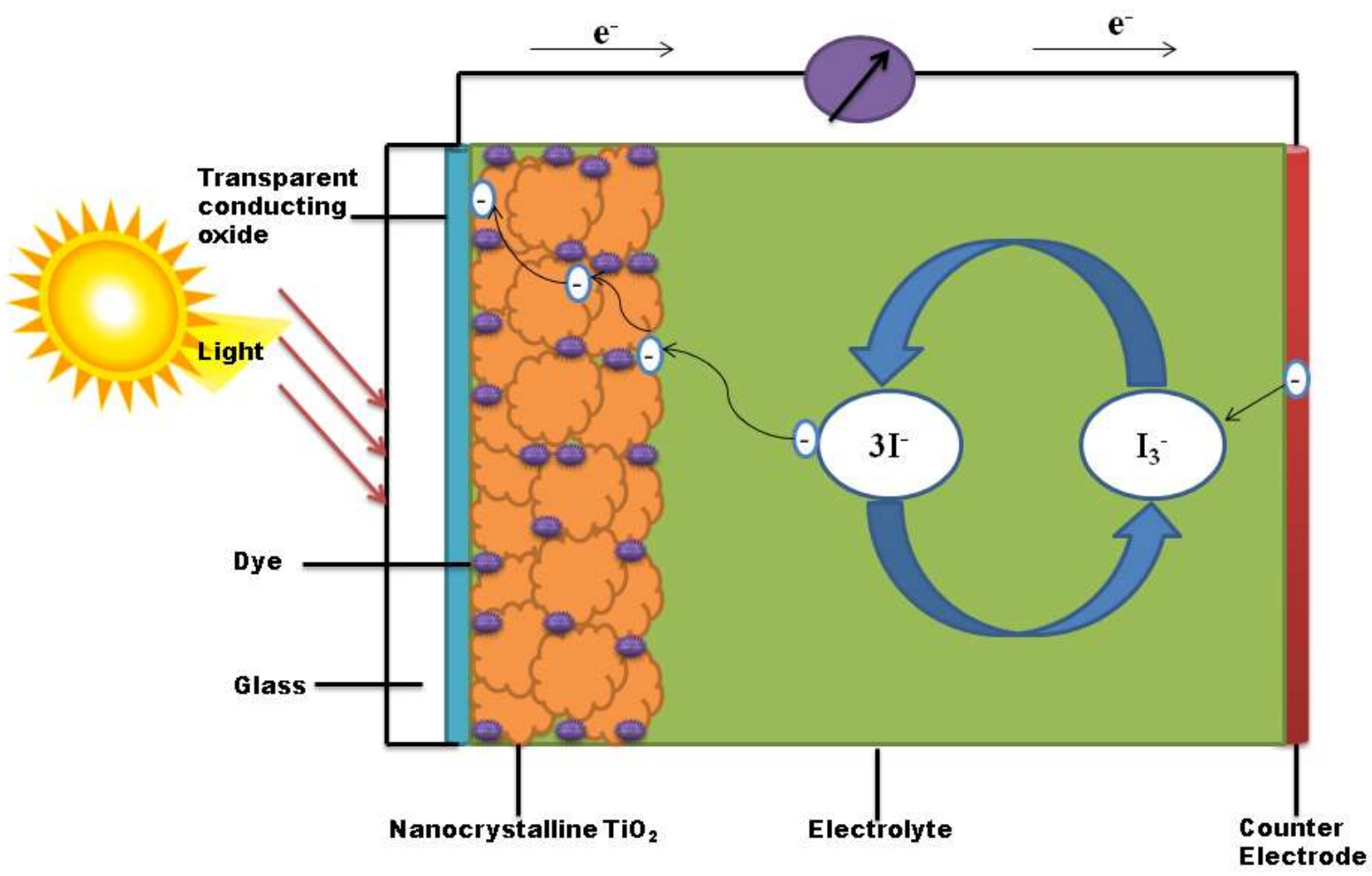

Fig.2 Construction and function of dye-sensitized nanocrystalline solar cells 


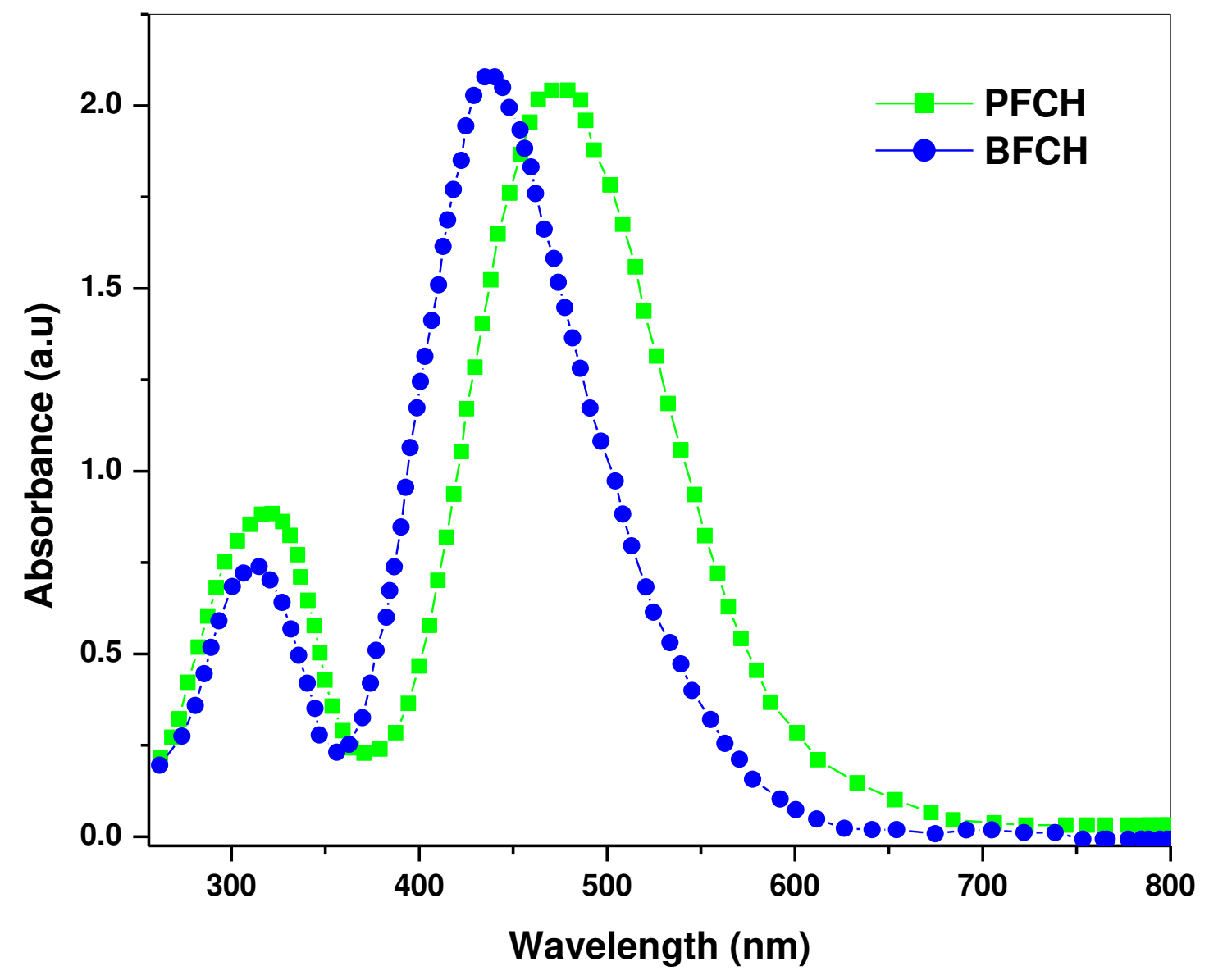

Fig.3 Absorption spectra of PFCH and BFCH 


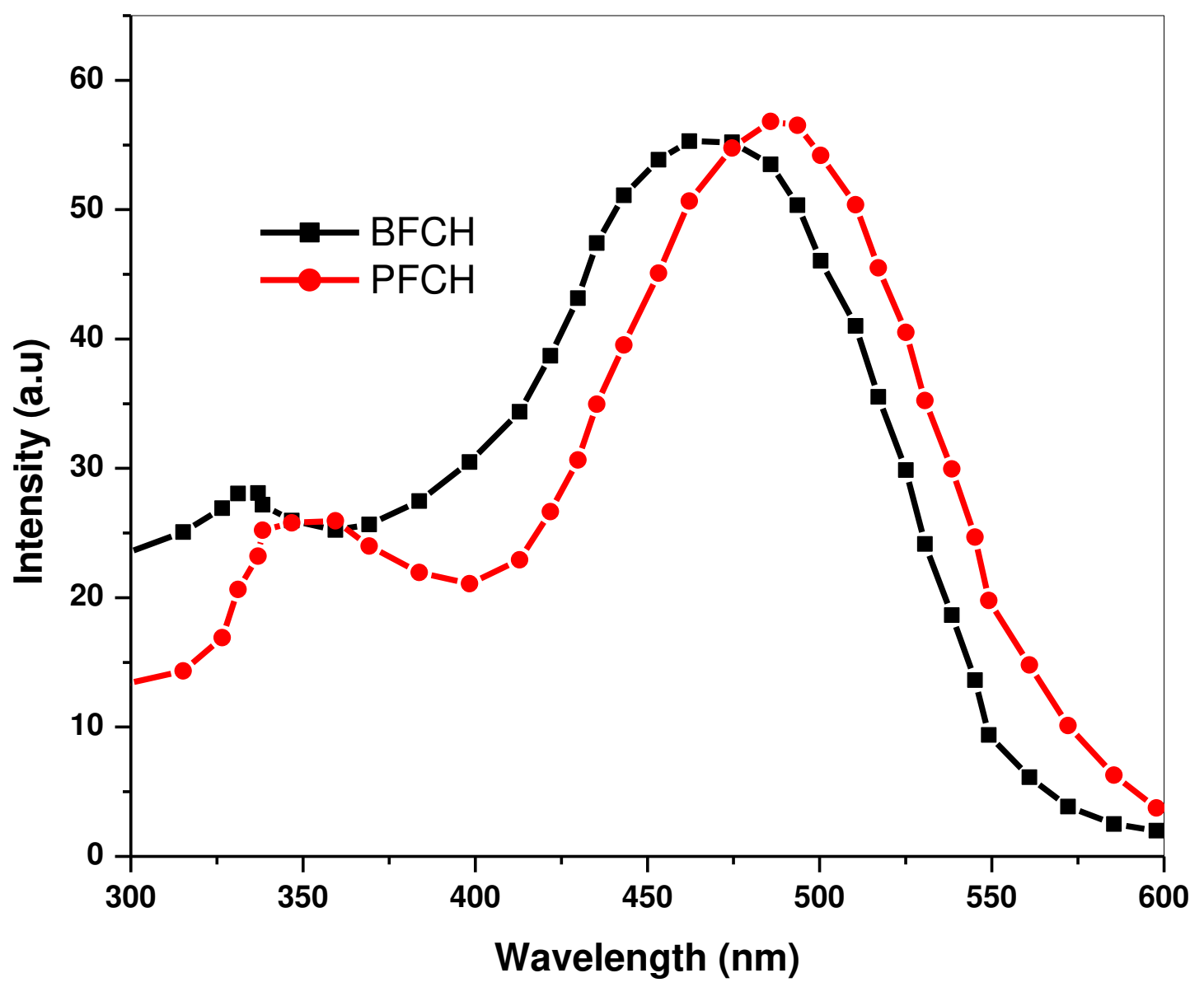

Fig.4 Absorption spectra of $\mathrm{TiO}_{2}$ electrodes sensitized of $\mathrm{PFCH}$ and $\mathrm{BFCH}$ 


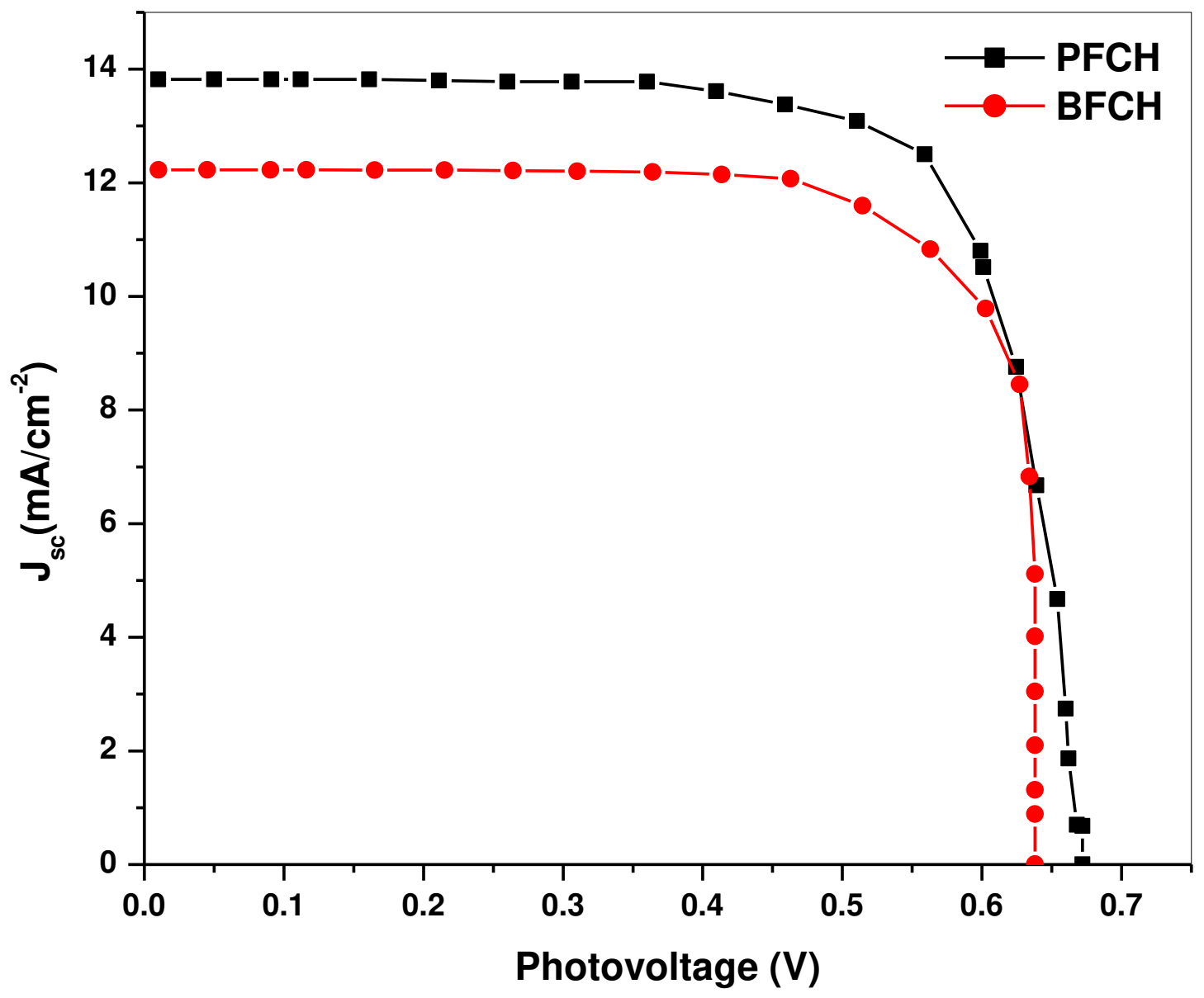

Fig.5 J-V characteristics calculated at an irradiation of $100 \mathrm{~mW} \mathrm{~cm}-2$ simulated 1.5 AM sunrays. 


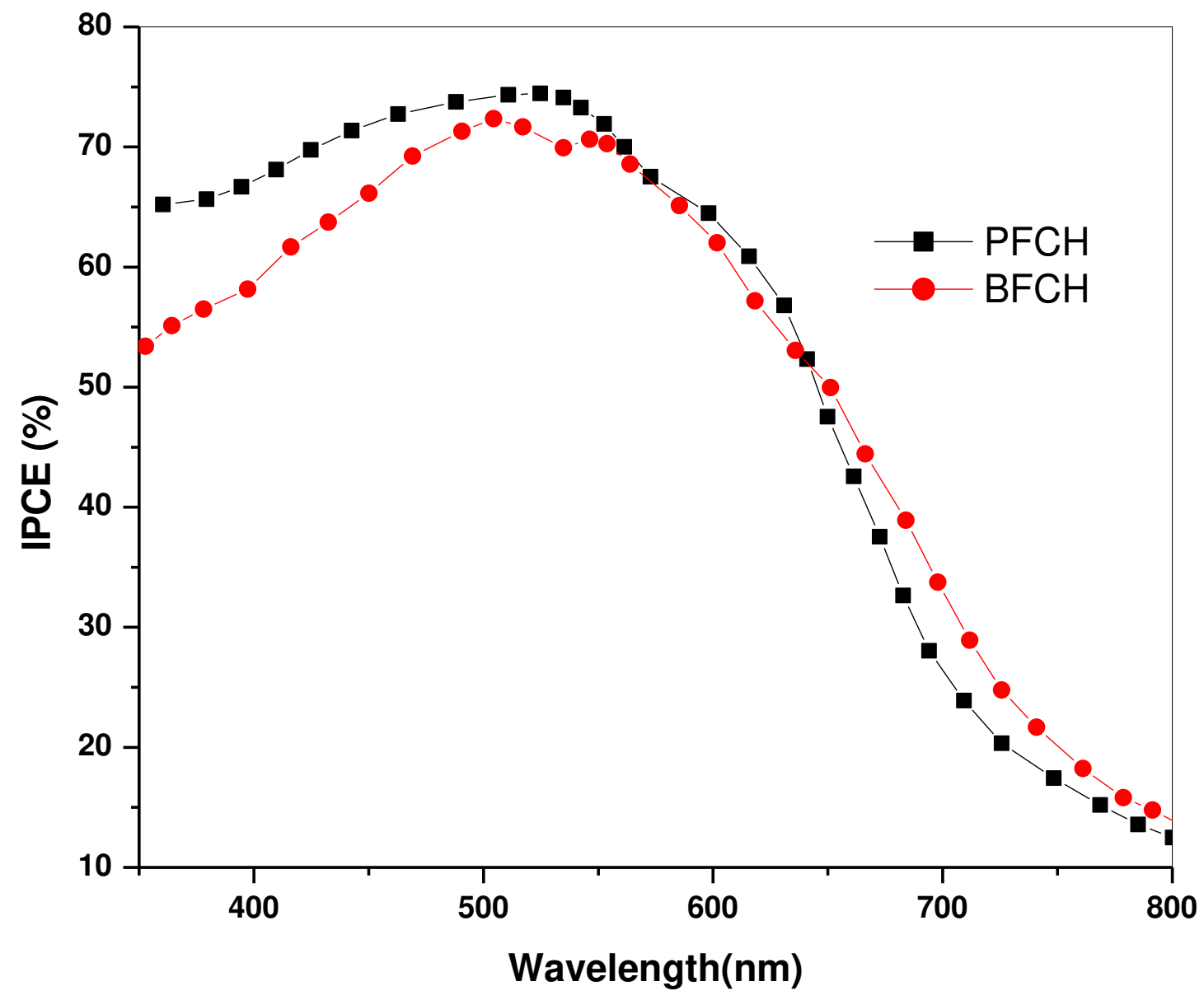

Fig.6 IPCEs spectra of PFCH and BFCH dyes 


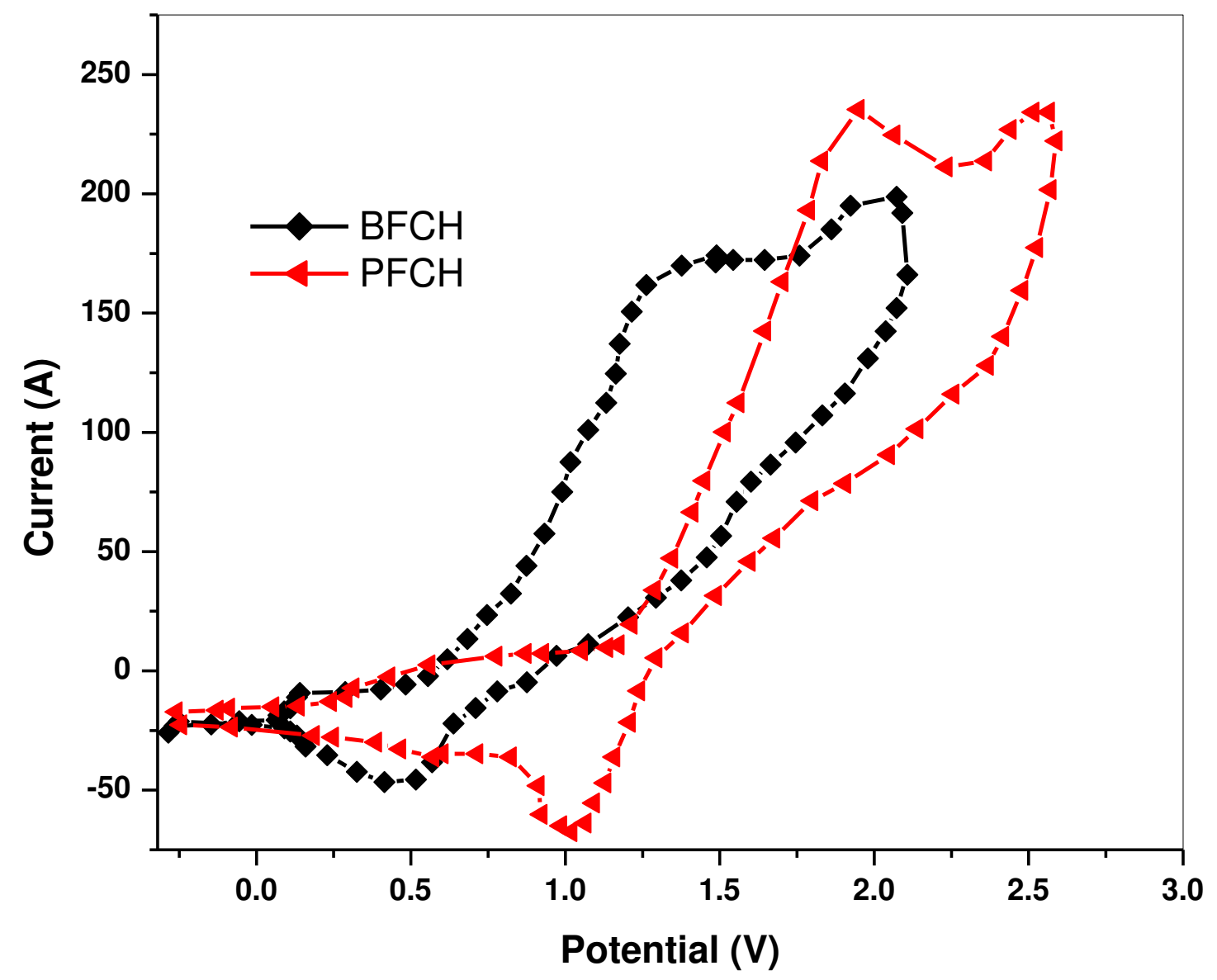

Fig.7 Cyclic voltammetry of PFCH and BFCH 


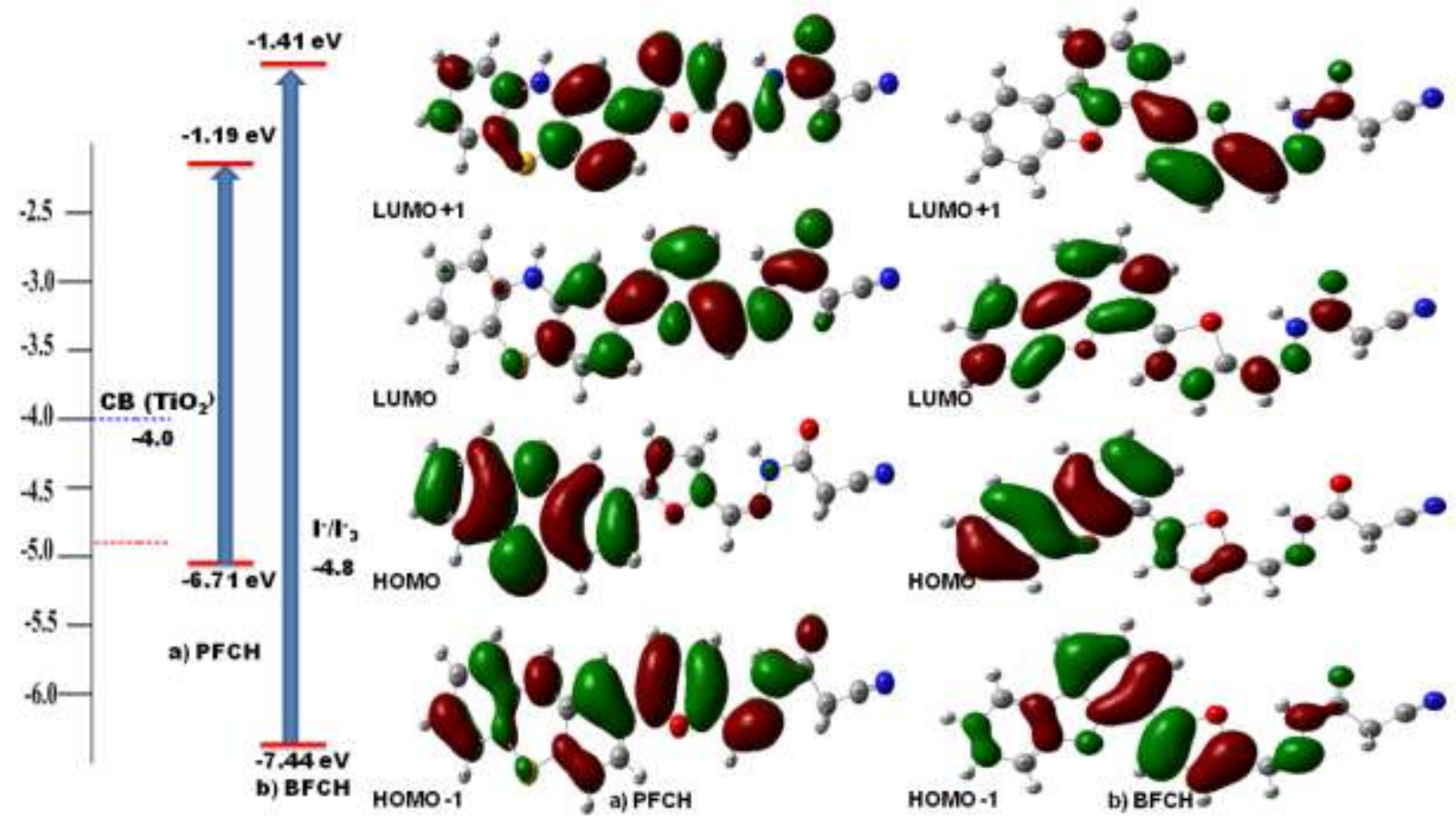

Fig.8 Frontier molecular orbitals and energy level diagram of PFCH and BFCH 

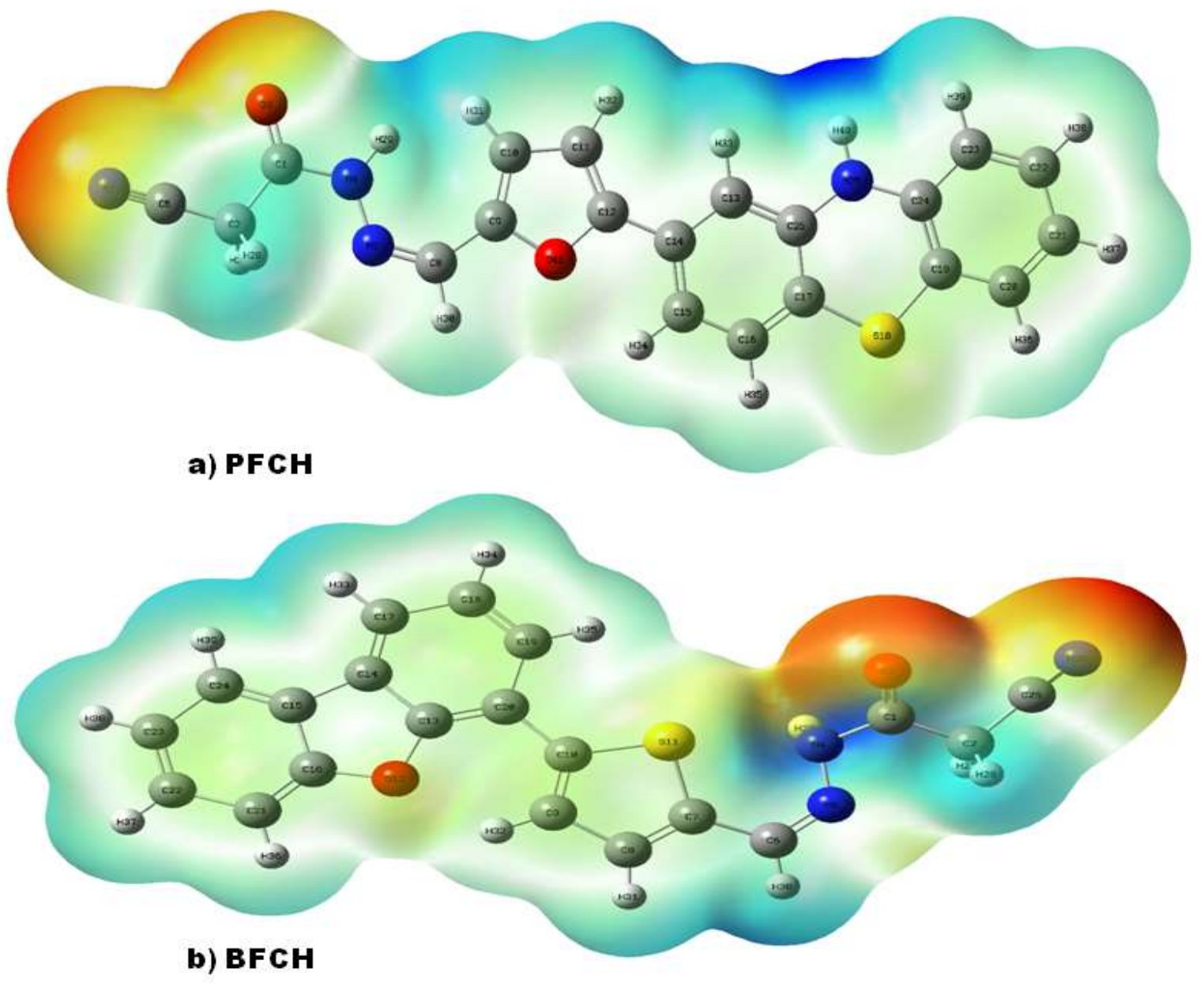

Fig.9 Molecular electrostatic potential images of studied molecules 

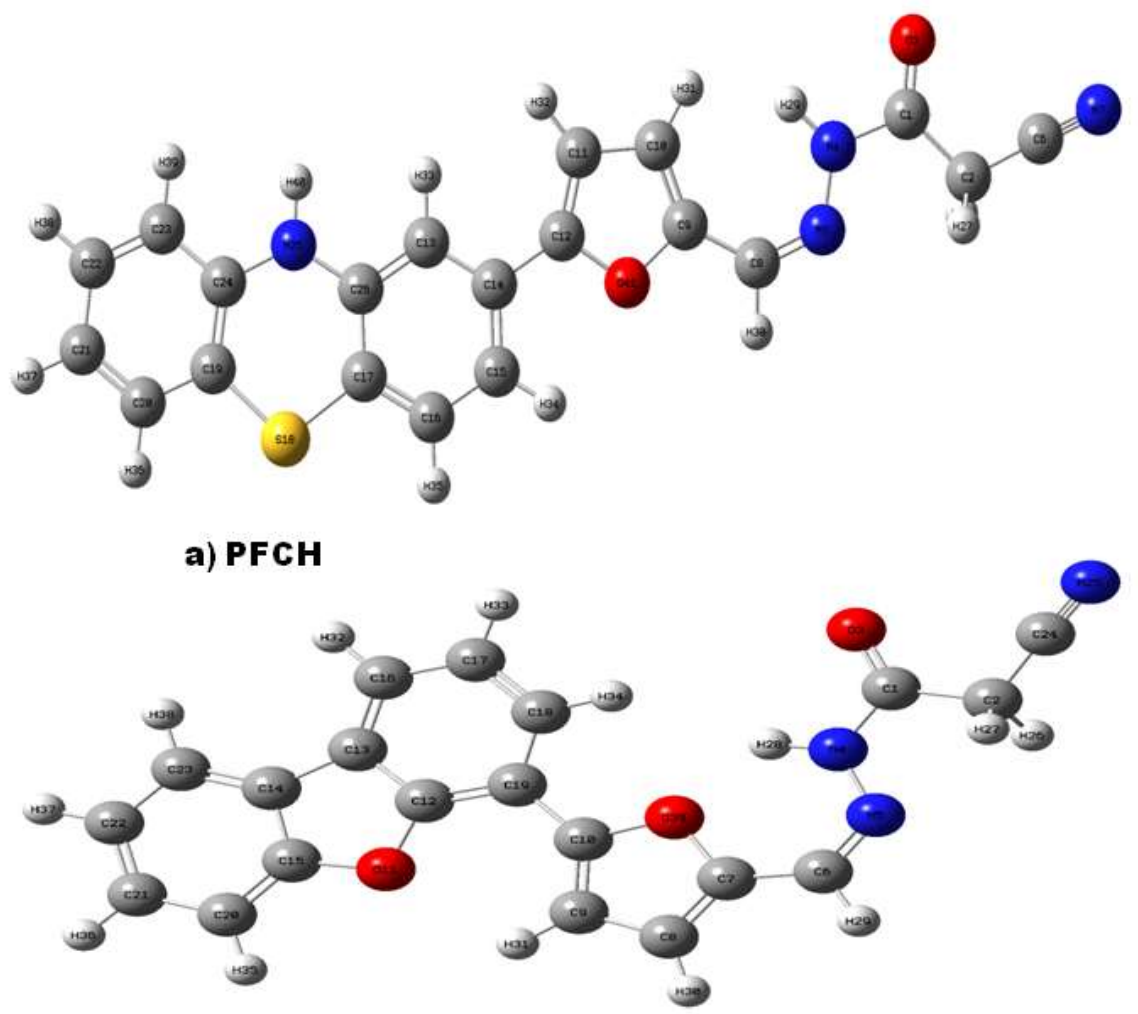

b) BFCH

Fig.10 Optimized molecular structure of PFCH and BFCH 
Table caption

Table 1: Observed absorption spectra, Oscillator strength (f), dipole moment, electronic transition and contribution of $\mathrm{PFCH}$ and $\mathrm{BFCH}$

\begin{tabular}{|c|c|c|c|c|c|c|c|}
\hline \multirow[b]{2}{*}{ Method } & \multirow[b]{2}{*}{ Dye } & & \multicolumn{5}{|c|}{ Parameters } \\
\hline & & $\begin{array}{l}\text { Dipole } \\
\text { Moment }\end{array}$ & $\begin{array}{c}\text { Observed } \\
\text { absorption } \\
\text { spectra }\end{array}$ & $\lambda_{\max }$ & $\mathrm{f}$ & $\begin{array}{l}\text { Electronic } \\
\text { transition }\end{array}$ & $\begin{array}{c}\text { Major \% } \\
\text { contribution }\end{array}$ \\
\hline \multirow{6}{*}{$\begin{array}{c}\text { TD-DFT } \\
\text { B3LYP/6- } \\
311++G \\
(\mathrm{~d}, \mathrm{p})\end{array}$} & \multirow{3}{*}{$\mathrm{PFCH}$} & \multirow{3}{*}{10.0356} & 468 & 462.31 & 0.8923 & $\mathrm{H} \rightarrow \mathrm{L}$ & $84.81 \%$ \\
\hline & & & 332 & 328.24 & 0.1172 & $\mathrm{H}-1 \rightarrow \mathrm{L}$ & $95.22 \%$ \\
\hline & & & 317 & 321.14 & 0.0031 & $\mathrm{H} \rightarrow \mathrm{L}+2$ & $59.84 \%$ \\
\hline & \multirow{3}{*}{$\mathrm{BFCH}$} & \multirow{3}{*}{9.1568} & 446 & 448.59 & 0.6881 & $\mathrm{H} \rightarrow \mathrm{L}$ & $84.22 \%$ \\
\hline & & & 328 & 314.25 & 0.0091 & $\mathrm{H}-1 \rightarrow \mathrm{L}$ & $94.74 \%$ \\
\hline & & & 309 & 312.17 & 0.1905 & $\mathrm{H} \rightarrow \mathrm{L}+2$ & $68.33 \%$ \\
\hline
\end{tabular}

Table 2: Photovoltaic performance of DSSCs based on PFCH and $\mathrm{BFCH}$

\begin{tabular}{|c|c|c|c|c|c|}
\hline Dye & $\mathrm{J}_{\mathrm{SC}}\left(\mathrm{mA} \mathrm{cm}^{-2}\right)$ & $\mathrm{V}_{\mathrm{oc}}(\mathrm{V})$ & $\mathrm{FF}$ & $\eta \%$ & $\begin{array}{l}\text { Adsorbed } \\
\text { amount of dye } \\
\left(\mathrm{mol.cm}^{-2}\right)\end{array}$ \\
\hline PFCH & 13.182 & 0.72 & 0.672 & 6.71 & $5.22 \times 10^{-7}$ \\
\hline BFCH & 12.231 & 0.68 & 0.638 & 5.39 & $5.13 \times 10^{-7}$ \\
\hline
\end{tabular}


Table 3: Electrochemical data and frontier molecular orbital energy levels of PFCH and BFCH

\begin{tabular}{|c|c|c|c|c|}
\hline Dye & ${ }^{\mathrm{a}} \lambda_{\max }(\mathrm{nm})$ & $\begin{array}{c}{ }^{\mathrm{b}} \mathrm{HOMO} \text { V(vs } \\
\text { NHE) }\end{array}$ & ${ }^{\mathrm{c}} \mathrm{E}_{0-0} / \mathrm{eV}$ & ${ }^{\mathrm{d}}$ LUMO/V (vs NHE) \\
\hline PFCH & 516 & 1.81 & 3.74 & -1.93 \\
\hline BFCH & 498 & 1.34 & 3.12 & -1.78 \\
\hline
\end{tabular}

a. Absorption maximum on $\mathrm{TiO}_{2}$ film. b. The HOMO levels were measured by cyclic voltammetry, see the experimental section for more details. c. $\mathrm{E}_{0-0}$ was estimated from the absorption thresholds from absorption spectra of dyes adsorbed on the $\mathrm{TiO}_{2}$ film. $\mathrm{d}$. LUMO is estimated by subtracting $\mathrm{E}_{0-0}$ from $\mathrm{HOMO}$

Table 4: Optical properties of PFCH and BFCH

\begin{tabular}{|c|c|c|}
\hline Optical properties & PFCH & BFCH \\
\hline \multirow{3}{*}{$\mathrm{f}$} & 0.8923 & 0.6881 \\
\hline & 0.1172 & 0.0091 \\
\hline & 0.0031 & 0.1905 \\
\hline \multirow{3}{*}{$\operatorname{LHE}\left(1-10^{-\mathrm{f}}\right)$} & 0.8719 & 0.7949 \\
\hline & 0.2366 & 0.0207 \\
\hline & 0.0072 & 0.3551 \\
\hline \multirow{3}{*}{$\lambda_{\max }(\mathrm{nm})$} & 462.31 & 448.59 \\
\hline & 328.24 & 314.25 \\
\hline & 321.14 & 312.17 \\
\hline \multirow{3}{*}{$\mathrm{E}_{(0,0)}(\mathrm{eV})$} & 4.46 & 4.12 \\
\hline & 3.75 & 3.96 \\
\hline & 3.98 & 3.95 \\
\hline $\mathrm{E}_{\text {Hомо }} \mathrm{eV}$ & -6.71 & -7.44 \\
\hline $\mathrm{E}_{\text {LUMO }} \mathrm{eV}$ & -1.19 & -1.41 \\
\hline Edye (eV) & 6.71 & 7.44 \\
\hline \multirow{3}{*}{$\mathrm{E}^{*}$ dye $(\mathrm{eV})$} & 2.25 & 3.32 \\
\hline & 2.96 & 3.48 \\
\hline & 2.73 & 3.49 \\
\hline
\end{tabular}




\begin{tabular}{|c|c|c|}
\hline $\mathrm{V}_{\text {oc }}$ & -5.19 & -5.41 \\
\hline \multirow{3}{*}{$\Delta \mathrm{G}_{\text {inject }}(\mathrm{Kcal} / \mathrm{mol})$} & -40.3568 & -15.6815 \\
\cline { 2 - 3 } & -23.9834 & -11.9917 \\
\cline { 2 - 3 } & -29.2875 & -11.7611 \\
\hline
\end{tabular}

Table 5: Quantum chemical parameters for studied molecules

\begin{tabular}{|c|c|c|}
\hline Parameters & PFCH & BFCH \\
\hline $\mathrm{E}_{\text {HOMO }}(\mathrm{eV})$ & -5.821 & -5.321 \\
\hline $\mathrm{E}_{\text {LUMO }}(\mathrm{eV})$ & -2.131 & -2.115 \\
\hline$\Delta \mathrm{E}$ & 3.691 & 3.204 \\
\hline Ionization energy (IE) & 5.821 & 5.321 \\
\hline Electron affinity (EA) & 2.131 & 2.115 \\
\hline$\mu$ & 3.976 & 3.718 \\
\hline$\chi$ & 3.976 & 3.716 \\
\hline$\eta$ & 1.845 & 1.602 \\
\hline$\sigma$ & 0.542 & 0.624 \\
\hline$\omega$ & 4.283 & 4.313 \\
\hline$\varepsilon$ & 0.234 & 0.232 \\
\hline$\omega^{+}$ & 2.526 & 2,655 \\
\hline$\omega^{-}$ & 6.502 & 6.372 \\
\hline$\Delta \mathrm{E}_{\text {back-donation }}$ & -0.462 & -0.401 \\
\hline DM & 9.471 & 9.064 \\
\hline
\end{tabular}




\section{Supplementary Files}

This is a list of supplementary files associated with this preprint. Click to download.

- Supportingfile.docx 